\title{
ORATIONES AD LAUDEM PURISSIME CONCEPTIONIS VIRGINIS MARIE: RECUPERACIÓN DE UN INCUNABLE / LITERATURA RECUPERADA*
}

\author{
Josep Lluís MARTOS \\ Universitat d'Alacant \\ jl.martos@ua.es
}

Cuando se marcan los límites de la literatura teniendo en cuenta las noticias de obras hoy perdidas, no solo se dispone de un panorama mucho más amplio para entender los hechos literarios concretos, sino que el catálogo establecido es también el punto de partida para la búsqueda y recuperación de esas obras, que tiene «la finalidad práctica de proporcionar una "lista de compras" para que los hispanomedievalistas sepan, al encontrar en una biblioteca o un archivo una obra que no conocen, si se trata de una obra que se creía perdida» ${ }^{1}$. Es, en definitiva, el estudio de la literatura perdida ${ }^{2}$ lo que hoy nos permite hablar de literatura recuperada y este es, de hecho, el objeto último de esta investigación.

\footnotetext{
* Este trabajo se enmarca en los proyectos FFI2014-52266-P y FFI2017-86313-P (AEI/ FEDER), de los cuales soy investigador principal. Esta es una investigación que se ha desarrollado durante cinco años, en el transcurso de la cual he contado con la inestimable ayuda de muchos colegas, que agradezco desde aquí: a Virginie Dumanoir, por los primeros contactos con los diferentes fondos bibliográficos de Langres; a Richart Dumanoir y a David Castro, por su apoyo en la traducción de los paratextos del incunable; a Antoni Biosca, por enseñarme a reconocer las abreviaturas latinas y revisar mi transcripción, en una primera versión, por lo que cualquier error que en ella quedase, sin duda sería exclusivamente mío. Agradezco también la colaboración de Hubert Déchanet, de la SHAL, y del Musée d'Art et d'Histoire de Langres, especialmente a Olivier Caumont, a Arnaud Vaillant y, sobre todo, a Anne-Guylaine Foret, que me ha facilitado la investigación en todos los sentidos, desde mi visita a Langres, hasta posteriores consultas concretas. Los Musées de Langres me han autorizado a la reproducción de las fotografías de este incunable perteneciente a sus colecciones, cuyos autores son AnneGuylaine Foret para las fotografías de las filigranas y yo mismo, para el resto de imágenes.

${ }^{1}$ Alan Deyermond, La literatura perdida de la Edad Media castellana: catálogo y estudio, I: épica y romances, Salamanca, Universidad de Salamanca, 1995, p. 19.

${ }^{2}$ A esta línea de estudio me he dedicado en los últimos años (Josep Lluís Martos, «La literatura perduda de Joan Roís de Corella: les fonts», Caplletra, 45 (2008), pp. 93-112; Id., «La literatura perdida de Joan Roís de Corella: límites, proceso y resultados de un catálogo», en Carlos Alvar (ed.), Estudios de literatura medieval en la Península Ibérica, San Millán de la Cogolla, Cilengua, 2015, pp. 123-145; Id., «La Suplicació de natura humana de Joan Roís de Corella: fragmentos recuperados de una obra perdida», Cultura Neolatina, 75/1-2 (2016), pp. 165-201. A ello me animó Alan Deyermond, siguiendo su ejemplo (La literatura perdida..., op. cit.) y el de su principal referente, R. M. Wilson, The Lost Literature of Medieval England [1952], Londres, Methuen, 1970.
} 
Hace un siglo y medio, el Ensayo de una biblioteca española de libros raros y curiosos de Bartolomé Gallardo incluyó una breve descripción de un incunable que en esos momentos era absolutamente desconocido por cualquier repertorio bibliográfico previo. Haebler se hizo eco de esta noticia ya en 1892, en su The Early Printers of Spain and Portugal, en una breve entrada: «1488, feb. 26. Diez, Orationes ad laudem purissimae conceptionis. Gallardo 2047» ${ }^{4}$. A partir de ella, Copinger ${ }^{5}$ incluye este incunable en su Suplemento al Repertorium Bibliographicum de Hain ${ }^{6}$, que no lo recogía: «Diez. Orationes ad laudem purissimae conceptionis. Valencia, Lambert Palmart, 1488, feb. 26». Poco después, Serrano y Morales ${ }^{7}$ reproducía, citándolos literalmente, los datos aportados por Gallardo ${ }^{8}$. Haebler desarrolla la referencia de su catálogo inglés en la Bibliografía ibérica del siglo $\mathrm{XV}^{9}$ y advierte de lo excepcional de esta noticia, porque «desde que Gallardo dió de este libro desconocido por Mendez las noticias antes copiadas nadie ha logrado verlo. Añade Gallardo la lista de los autores cuyas producciones se reunieron en el texto, pero no indica donde existe el ejemplar. Ni el Sr. Serrano ni yo hemos visto ninguno» ${ }^{10}$. Francisco Vindel, que depende de manera directa de Haebler, incide en que «de esta obra no se conocen más noticias

${ }^{3}$ Bartolomé José Gallardo, Ensayo de una biblioteca española de libros raros y curiosos, 4 vols., Madrid, Imprenta y Estereotipia de M. Rivadeneyra-Imprenta y Fundición de Manuel Tello, 1865-1889, vol. 2, pp. 797-798, n. ${ }^{\text {o }} 2047$.

${ }^{4}$ Konrad Haebler, The Early Printers of Spain and Portugal, Londres, Bibliographical Society at the Chiswick Press, 1897, p. 92.

${ }^{5}$ Walter Arthur Copinger indica que su fuente es «Haebler, p. 92», cuya paginación coincide y cuya fecha permite la correspondiente inclusión al final de su Supplement to Hain's Repertorium Bibliographicum, 2 tomos en 3 vols., Londres, Henry Sotheran and Co., 1895-1902, II/2, p. 307, n. ${ }^{\circ} 1975$ a.

${ }^{6}$ Ludwig Hain, Repertorium bibliographicum, in quo libri omnes ab arte tipographica inventa usque ad annum MD, Stuttgart, Lutetiae Parisiorum, 1826-1838, 2 vols.

${ }^{7}$ José Enrique Serrano y Morales, Reseña histórica en forma de diccionario de las imprentas que han existido en Valencia desde la introducción del arte tipográfico en España hasta el año 1868 con noticias bio-bibliográficas de los principales impresores, València, Imprenta de F. Doménech, 1898-1899, p. 451.

${ }^{8}$ A excepción del listado de autores participantes, Bartolomé José Gallardo, Ensayo de una biblioteca..., op. cit., vol. 2, pp. 797-798, n. ${ }^{\circ} 2047$.

${ }^{9}$ Aunque siguiendo los datos físicos aportados por Gallardo: «Diez, Fern. Orationes ad laudem purissimae conceptionis. - Valencia, por Lamberto Palmart, 1488, 26 de febrero. $4^{\circ}$. - 26 hjs no fols. — sign: $\mathrm{ab}^{8} \mathrm{c}^{10}$. — á linea tirada. — letra gótica», Konrad Haebler, Bibliografia ibérica del siglo XV. Enumeración de todos los libros impresos en España y Portugal hasta el año de 1500, La Haya-Leipzig, Martinus Nijhoff-Karl W. Hiersemann, 1903, p. 105, n. ${ }^{\circ} 229$.

${ }^{10} \mathrm{Ibid}$. Askins destaca la Biblioteca de Gallardo como una fuente privilegiada para el conocimiento de la literatura perdida: «Los eruditos que anteriormente habían parado mientes en los registros como gran fuente de información y documentación primaria, sobre todo a partir de las papeletas y extractos de Gallardo, advertían claramente la necesidad de revisarlos sistemáticamente», Arthur L.-F. Askins, «Muestrario de incunables hispánicos extraviados de la Biblioteca Colombina», en María Luisa López-Vidriero y Pedro M. Cátedra (eds.), El libro antiguo español. Actas del Primer Coloquio Internacional (Madrid, 18 al 20 de diciembre de 1986), Salamanca, Ediciones Universidad de Salamanca-Biblioteca Nacional de EspañaSociedad Española de Historia del Libro, 1988, pp. 37-53, p. 37. 
que las que transcribimos, y que fueron dadas por Gallardo, sin decir dónde se conservaba el ejemplar citado» ${ }^{11}$. Palau y Dulcet ${ }^{12}$, poco después, se limita a reproducir datos dependientes de Gallardo, como el resto de bibliógrafos posteriores. Romero Lucas recoge de Haebler y Vindel la cuestión del aparente olvido de Gallardo, que, según ellos, habría dificultado su localización durante ese siglo y medio: «La descripción la tomaron ambos bibliógrafos [Haebler y Vindel] de Gallardo, que no indicaba dónde se encontraba el ejemplar» ${ }^{13}$.

Frente a ello, Askins no duda de que el incunable fuese propiedad de Gallardo: «transcribe la portada del ejemplar que poseyó»» ${ }^{14}$. Tenemos constancia de que la descripción de este impreso depende de sus fichas originales -pues las que no son de su autoría se marcan con un asterisco-, pero también la tenemos de que este incunable le perteneció fehacientememte, porque buena parte de este catálogo, como indica su título, es el de una biblioteca concreta, la del propio Gallardo, y de ella formaban parte la mayoría de los libros descritos. Pero esto no solo lo sabemos implícitamente, sino que Gallardo lo explicita, aunque no en esta entrada de su catálogo, sino en la anterior, de cuyo incunable en cuestión advertía que «el impresor, si mal no me acuerdo, era Lamberto Palmart, donde imprimió en $4 .^{\circ}$ el mismo mosen Fernando Diez las "Oraciones latinas" pronunciadas en este certámen de la virgen por Miguel Perez, Juan Lopez, Mateo Perez, Dr. Fernando Belluga, Estéban Costa, etc., libro también escasísimo, de que poseo ejemplar, único que he alcanzado á ver, ni sepa que nadie vió otro tal $\rangle^{15}$. Era consciente, por tanto, de la singularidad de este ejemplar de su biblioteca. Por ello, confinado en una o varias bibliotecas privadas, la pérdida de su rastro tras su muerte limitó el conocimiento de este incunable por parte de los bibliógrafos y de la crítica especializada durante alrededor de un siglo.

Valga como ejemplo paradigmático que Antoni Ferrando se tuvo que conformar con las breves notas de Gallardo para desarrollar, en un verdadero ejercicio de exégesis, el capítulo del certamen poético que dio lugar a este incunable: «El tercer certamen immaculista convocat per Ferrando Díeç, de què tenim notícia, és el que donà lloc a un quasi desconegut incunable, que no hem sabut localitzar» ${ }^{16}$. Solo cuatro años antes, sin embargo, se había documentado su existen-

${ }^{11}$ Francisco Vindel, El arte tipográfico en España durante el siglo XV: Valencia, Mallorca y Murcia, Madrid, Ministerio de Asuntos Exteriores-Dirección General de Relaciones Culturales, 1946, p. 76, n. $^{\circ} 26$.

${ }^{12}$ Antonio Palau y Dulcet, Manual del librero hispanoamericano, 28 vols., Barcelona, Librería Palau, 1948-1977, vol. 4, n. ${ }^{\circ} 73676$.

${ }^{13}$ Diego Romero Lucas, Catálogo gráfico descriptivo de la imprenta en Valencia 1473 1530, 3 vols., Valencia, Universitat de València, 2005 [tesis doctoral], vol. 2, p. 129, n. ${ }^{\circ} 25$.

${ }^{14}$ Arthur L.-F. Askins, «Muestrario de incunables...», art. cit., p. 46.

${ }^{15}$ Bartolomé José Gallardo, Ensayo de una biblioteca..., op . cit., vol. 2, p. 797, n. ${ }^{\circ} 2046$.

${ }^{16}$ Antoni Ferrando Francés, Els certàmens poètics valencians, València, Institució Alfons el Magnànim, 1983, p. 557. 
cia en una biblioteca francesa de la región de Champagne-Ardenne, dentro del proyecto de catalogación de las bibliotecas regionales de Francia y mediante una brevísima entrada que lo identificaba como incunable 44 de la Société Historique et Archéologique de Langres (SHAL) ${ }^{17}$.

Allí lo localizan el Gesamtkatalog der Wiegendrucke "Langres SocHist $\rangle^{18}$ y el Incunabula Short Title Catalogue 《Langres SHAL $\gg{ }^{19}$, pero este dato es incorrecto a día de hoy, como demostraré aquí, junto a otras dificultades añadidas para la recuperación de este incunable $\mathrm{y}$, con ello, de las obras que contiene, cuya pista surgió y se perdió en la segunda mitad del siglo XIX. En este artículo, reconstruyo, asimismo, su historia a lo largo del siglo xx y, posiblemente, desde fechas cercanas a su pertenencia a la biblioteca de Gallardo. Las especulaciones sobre él y los escasos datos aportados por este bibliógrafo, son revisados, corregidos y ampliados en la segunda parte del trabajo, desde la materialidad del impreso, cuya recuperación permite, a su vez, una descripción interna, con la que no contábamos hasta ahora y que nos desvela datos como el mismísimo ganador de la contienda poética. Estos son, en definitiva, los objetivos de este trabajo.

\section{LA RECUPERACIÓN DEL INCUNABLE}

La suerte quiso que la noticia de este incunable emergiera gracias a la combinación de dos factores: por un lado, la llegada del importante legado bibliófilo de su anterior poseedor a una biblioteca local $\mathrm{y}$, por otro lado, la puesta en marcha de un proyecto para elaborar los Catalogues régionaux des incunables des bibliothèques publiques de France, cuyo primer volumen se dedica, precisamente, a las $B i$ bliothèques de la Région Champagne-Ardenne ${ }^{20}$, en una de les cuales se encontraba entonces este impreso. Se trata de una biblioteca de Langres, una pequeña localidad del Alto Marne ${ }^{21}$, en el noroeste de Francia, donde Jean-Marie Arnoult, el conservador de la Biblioteca Municipal de Châlons-en-Champagne, del departamento del Marne, refiere la existencia de un ejemplar de este incunable desconocido. El repertorio de Arnoult ofrece una breve ficha bibliográfica bajo dos números diferentes, con carácter meramente convencional y

\footnotetext{
${ }^{17}$ Jean-Marie Arnoult, Catalogues régionaux des incunables des bibliothèques publiques de France, I. Bibliothèques de la Région Champagne-Ardenne, Bordeaux, Societé des Bibliophiles de Guyenne, 1979, p. 107, n. ${ }^{\circ} 525$ y 393, n. ${ }^{\circ} 149$.

${ }_{18}$ GW-Gesamtkatalog der Wiegendrucke, Leipzig, K. V. Hiersemann, 1925-actualidad, n. ${ }^{\circ}$ 08344, en línea: <http://www.gesamtkatalogderwiegendrucke.de> [consulta: 24/06/2019].

${ }^{19}$ ISTC-Incunabula Short Title Catalogue, Londres, British Library, n. ${ }^{o}$ id00192100, en línea: <http://www.bl.uk/catalogues/istc> [consulta: 24/06/2019].

${ }^{20}$ Jean-Marie Arnoult, Catalogues régionaux..., op. cit.

${ }^{21}$ Uno de los cuatro departamentos de la región de Champaña-Ardenas; los otros tres son Ardenas, Aube y Marne. Langres es conocida, sobre todo, por ser la ciudad natal de Denis Diderot, el padre de la Encyclopédie.
} 
limitados a este repertorio: el 525 para el catálogo general ${ }^{22}$ y el 149 para el específico de la Société Historique et Archéologique de Langres (SHAL) ${ }^{23}$, en ambos casos bajo el título de Orationes in laudem purissime matris Domini.

A pesar de que Arnoult referencia el Gesamtkatalog der Wiegendrucke como una de las fuentes bibliográficas para este incunable, en el que se cataloga con el número 08344, este partía y se limitaba entonces a la información de Gallardo mediatizada por Haebler y desconocía, por tanto, la localización del ejemplar conservado. Este proyecto alemán, que buscaba actualizar el repertorio de Hain ${ }^{24}$, sustituyéndolo, comenzó su publicación en 1925, en cuyo séptimo volumen se incorpora este impreso. En esas fechas, anteriores a 1940, no había llegado aún a la SHAL esta colección de incunables, que seguía en manos privadas, por lo que, entonces, aún se desconocía su localización; ni siquiera la reedición de los ocho primeros volúmenes en 1968 incorporaba aún la referencia al lugar de conservación de este ejemplar incunable, sino que fue el GW en línea ${ }^{25}$, que entró en funcionamiento en octubre de 2003, el que se actualizó para recoger la noticia de Arnoult. El Incunabula Short Title Catalogue no avanza en los datos descriptivos ${ }^{26}$. Aunque ambos catálogos en línea refieren la SHAL como fondo que lo custodia, no indican que tenía la signatura 44, para lo que tenemos que recurrir al catálogo de Arnoult ${ }^{27}$.

Llegados a este punto, parecía un hecho la recuperación de este incunable perdido, cuya reproducción solicité a la SHAL por escrito en dos ocasiones, aportando la signatura concreta de su fondo y la descripción correspondiente, a partir de los datos de Gallardo. La gestión, sin embargo, no tuvo éxito ni respuesta ${ }^{28}$, hasta que, en mayo de 2014, me puse en contacto telefónico con el encargado de esta biblioteca, Hubert Déchanet, y me explicó que esta Sociedad ya no tenía en custodia ningún fondo antiguo, ni bibliográfico ni artístico, sino que había pasado al Musée d'Art et d'Histoire de Langres ${ }^{29}$. Déchanet se ofreció a consultar él mismo la posibilidad de reproducción $\mathrm{y}$, ante ello, recibió por respuesta que este incunable ya no estaba

\footnotetext{
${ }^{22}$ Jean-Marie Arnoult, Catalogues régionaux..., op. cit., p. 107.

${ }^{23}$ Ibid., p. 393

${ }^{24}$ Ludwig Hain, Repertorium bibliographicum..., op. cit.

${ }^{25}$ Gesamtkatalog der Wiegendrucke, op. cit.

${ }^{26}$ Incunabula Short Title Catalogue, op. cit., n. ${ }^{\circ}$ id00192100.

${ }^{27}$ Jean-Marie Arnoult, Catalogues régionaux..., op. cit., p. 107, n. ${ }^{\circ} 525$ y p. 393, n. ${ }^{\circ} 149$.

${ }^{28}$ Algo parecido debió de ocurrir a Romero Lucas y, de ahí, que no hubiese conseguido
} tampoco una reproducción del incunable, ni indique otra noticia respecto al paradero de este ejemplar único de las Orationes: «En el ISTC se indica que un ejemplar de esta obra se encuentra en la Biblioteca se la Sociedad Arqueológica e Histórica de Langres (Francia). La obra no ha podido llegar a tiempo para incluir las imágenes», Diego Romero Lucas, Catálogo gráfico descriptivo..., op. cit., vol. 2, p. 129, n. ${ }^{\circ} 25$.

${ }^{29} \mathrm{Al}$ que me refiero, de manera abreviada, como Musée de Langres o, cuando lo hago en plural, es porque me refiero a los dos museos previos de esta localidad, cuyos fondos se reúnen en la ubicación actual. 
tampoco entre los fondos del Musée de Langres. La noticia era decepcionante, porque ya Arnoult refería en 1979 la pérdida de siete incunables de esta colección ${ }^{30}$. La conservación del fondo debió de ser precaria a la luz de estas pérdidas y no auguraba éxito, por tanto, a esta investigación.

Tras ponerme en contacto con el conservador de los Museos de Langres, Olivier Caumont, como máximo responsable de esta colección de incunables, me derivó a Anne-Guylaine Foret, documentalista del Museo, quien me confirmó que el incunable no se encontraba ya en su colección. Ante la nueva pérdida de este ejemplar único del incunable y la cercanía en fechas del catálogo de Arnoult, de tan solo treinta y cinco años de antigüedad, solicité la posibilidad de visitar el Museo para revisar in situ el fondo completo, para comprobar el modelo de conservación de los incunables, para llevar a cabo una búsqueda sistemática atendiendo a las diferentes posibilidades de extravío y, si se hubiese dado el caso, para cerrar este trabajo con la conclusión decepcionante de que el incunable de las Orationes ad laudem purissime conceptionis, que ya había pasado de la SHAL a los Musées de Langres, había vuelto a perderse.

El 12 de junio de 2014 pude llevar a cabo tal visita y me dieron acceso a las tres estanterías que conservaban los 340 incunables del fondo, que estaban ordenados bajo una nueva catalogación ${ }^{31}$, según la cual la signatura actual de este incunable en el Musée d'Art et d'Histoire de Langres era 943-1-89, indicada en un pequeño trozo de cartulina insertado en la parte superior, de consulta poco ágil y de una cierta inestabilidad y fragilidad de conservación ${ }^{32}$. El lugar que le correspondería se encontraba en el primer armario, en la penúltima balda de la parte inferior, en la fila interna. El orden de los incunables seguía, a grandes rasgos, esta nueva signatura, jugando en algunos casos con los tamaños de estos, e incluyendo una doble o triple hilera en ocasiones -a veces incluso en perpendicular, al fondo del armario o en la parte más externa. Entre los impresos 943-1-88 y 943-1-90 había, efectivamente, un salto de numeración y la documentalista del Museo, Anne-Guylaine Foret, me confirmaba que se habían revisado individualmente todos los volúmenes, tanto por la signatura actual, como por la antigua de la SHAL ${ }^{33}$, sin éxito. Insistí, sin embargo, en volverlo a hacer, porque, por su grosor, de solo 26 hojas, y estando en una hilera interna, podría haberse quedado dentro de otro incunable de los tantos de gran formato que conserva el Museo, haberse

${ }^{30}$ Jean-Marie Arnoult, Catalogues régionaux..., op. cit., p. 407.

${ }^{31}$ Que dejaba anticuada la sign. 44 de la SHAL, ofrecida por Arnoult, ibid., p. 107, n. ${ }^{\circ} 525$ y p. 393, n. $^{\circ} 149$.

${ }^{32} \mathrm{La}$ correspondencia con las signaturas antiguas es un documento interno manuscrito a bolígrafo.

${ }^{33}$ El Museo cuenta con una tabla de equivalencias entre ambas signaturas, que pude revisar para el cotejo con el catálogo completo de Arnoult, ibid. 
caído entre los huecos de los estantes de metal ${ }^{34}$, estar en el fondo en situación horizontal o perpendicular al sentido de los volúmenes o, simplemente, estar desordenado en la secuencia de signaturas. Con la supervisión de Foret, extraje uno a uno los incunables personalmente, revisándolos, abriéndolos, dejando vacíos los estantes para comprobar cualquier recoveco del armario por el que se hubiese podido colar este volumen. Conforme avanzaba la búsqueda, se desvanecía la posibilidad de encontrarlo y, de hecho, lo hizo por completo al abrir el tercero de los armarios y comprobar que solo la parte superior contenía incunables y estos eran, fundamentalmente, de gran tamaño. El resto del armario contenía impresos modernos y un estante inmediatamente inferior al de los incunables, con muchos papeles contemporáneos desordenados y libros encuadernados en pergamino que Foret me indicaba que no eran ya del siglo xv, sino impresos de los siglos XVI y XVII. Entre ese desorden, había un pequeño montón de libros encuadernados en pergamino y, al revisarlos, comprobé que el tercero de ellos tenía en su cubierta la siguiente inscripción, precedida de un calderón: $\mathbb{P}$ Orationes Ad laudem purissime / conceptionis virginis Marie.

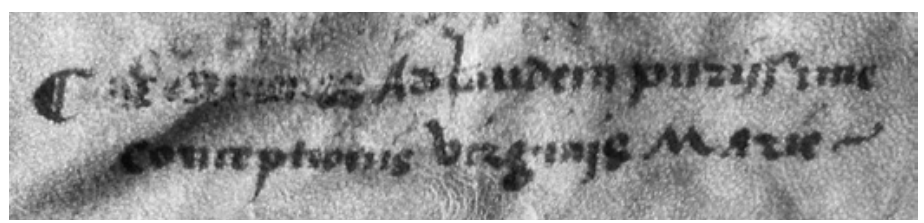

(C) Collections des Musées de Langres

Este título es el que transmite, por primera vez, Copinger y, después, Haebler, Vindel ${ }^{35}$, Romero Lucas y el Gesamtkatalog der Wiegendrucke $^{36}$. Frente a este fórmula, Arnoult ofrece la de Orationes in laudem purissime matris Domini ${ }^{37}$, que pasa, exclusivamente, al ISTC $^{38}$. Tanto un título como el otro, sin embargo, presentan el genitivo purissimae en la forma clásica, a excepción de Arnoult, que, al consultarlo directamente, incorpora la forma medieval purisime ${ }^{39}$. El incunable no presenta título, sensu stricto, pero una mano antigua

${ }^{34}$ Se trata de los típicos armarios de almacenamiento, con cierta holgura entre el fondo y los estantes.

${ }^{35}$ Francisco Vindel, El arte tipográfico en España..., op. cit., p. 76, n. ${ }^{\circ} 26$.

${ }^{36}$ Walter Arthur Copinger, Supplement to Hain 's..., op. cit., p. 307, n. ${ }^{\circ}$ 1975a; Konrad Haebler, The Early Printers..., op. cit., p. 92; Konrad Haebler, Bibliografia ibérica..., op. cit.,

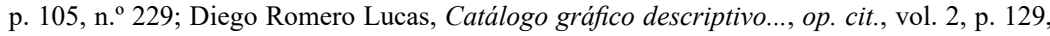
n. ${ }^{\circ} 25 ;$ Gesamtkatalog der Wiegendrucke, op. cit., n. ${ }^{\circ} 08344$.

${ }^{37}$ Jean-Marie Arnoult, Catalogues régionaux..., op. cit., p. 107, n. ${ }^{\circ} 525$ y p. 393, n. ${ }^{\circ} 149$.

${ }^{38}$ Incunabula Short Title Catalogue, op. cit., n. ${ }^{\circ}$ id00192100.

${ }^{39}$ En cualquier caso, si Walter Arthur Copinger, Supplement to Hain 's..., op. cit., p. 307, n. ${ }^{\circ}$ 1975a, hubiese sido fiel a la transcripción paleográfica que hizo Bartolomé José Gallardo, Ensayo de una biblioteca..., op . cit., vol. 2, p. 797, n. ${ }^{\circ}$ 2047, de las rúbricas iniciales y del colofón, podría haber transcrito purissime, así como los bibliógrafos posteriores. 
lo establece en la cubierta del ejemplar, no ex novo, sino a partir del colofón: «Jmpresse fuerunt predicte orationes ad laudem pu/ | rissime conceptionis virginis marie per lambertum | palmart...» (c10r). Arnoult extrae la fórmula «in laudem purissime matris Domini» de las rúbricas del libellum y de los textos presentados al certamen ${ }^{40}$, reconstruyendo el término Orationes al principio de ella. Es por ello que opto por la solución literal del colofón, que, además, se refiere al volumen impreso, en su conjunto, como también entendió quien transcribió este título en su cubierta.

El incunable había perdido tanto el tejuelo original de la SHAL como la cartulina con la signatura nueva del Musée de Langres y de ahí la dificultad para su localización por parte de los conservadores del fondo. Bien por las prisas tras la consulta de algún lector o bien por la pérdida de los tejuelos, se dejó algunos volúmenes fuera de lugar para volver a ser ordenados o clasificados y eso no llegó a ocurrir. Hoy, en cualquier caso, este incunable se ha recuperado para la crítica especializada, cuyo único ejemplar se conserva en el Musée d'Art et d'Histoire de Langres, con signatura 943-1-89.

\section{TABLA DE REFERENCIAS DEL INCUNABLE}

Catalogue des incunables des Bibliothèques de la Région Champagne-Ardenne $e^{41}$ 525

Société Historique et Archéologique de Langres 44
Catalogue des incunables de la Société Historique et Archéologique de Langres ${ }^{42}$ 149

Musée d'Art et d'Histoire de Langres 943-1-89

\section{De la BIBLIOFILIA DECIMONÓNICA AL MUSÉE DE LANGRES}

En la contracubierta delantera de este ejemplar de las Orationes ad laudem purissime conceptionis, encontramos el ex-libris del último bibliófilo que poseyó este incunable ${ }^{43}$, común a la mayoría de la colección, pues buena parte del fondo bibliográfico de las colecciones de los Musées de Langres proviene de su legado:

\footnotetext{
${ }^{40}$ Aunque no siempre idéntica y, si bien está precedida en unos casos por oratio/oracio, no siempre es así, sino que en otros se inicia con libellum o triunphus: «Libellum nobilis viri ferdinandi dieç presbiteri qui | in laudem purissime matris domini munus obtulit» (a1r-v); «Oracio eloquentissima in laude $m$ purissime matris domini $\mid$ conceptionis...» (a2v); «Oratio suptilissima in laudem purissime matris do $\mid$ mini conceptionis...» (a7v); «Trihunphus in laudem purissime conceptionis matris $\mid$ domini...» (b4r); «Oratio [...] in laudem purissime con | ceptionis matris domini» (c2r); «Oracio habita in laudem purissime concepcionis matris | domini» (c5v).

${ }^{41}$ Jean-Marie Arnoult, Catalogues régionaux..., op. cit., p. 107.

${ }^{42}$ Ibid., p. 393.

${ }^{43}$ Se trata de un grabado que en algunas piezas - no en este caso- está coloreado manualmente.
} 


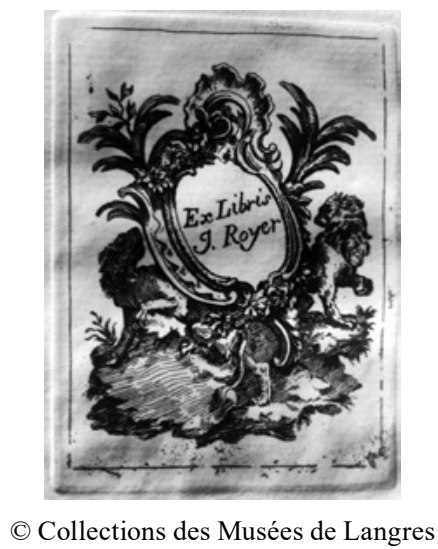

Se trata de Joseph Royer, nacido en 1850 en Langres, cuyo patrimonio no podemos deslindar del de su hermano Charles, dos años mayor que él. El primero murió en 1941, más de veinte años antes que el primogénito, fallecido en 1920; fue durante este período de veintiún años, por lo tanto, cuando Joseph incluyó su ex-libris en la colección que había pertenecido a ambos hermanos. Descendían «d'une vieille famille bourgeoise de Sompuis (Marne), d'ont une branche, restée au bourg ancestral, a donné naissance à l'illustre philosophe, orateur et homme d'Etat du même nom [=Nicolas Royer] qui a joué un si grand rôle en France durant la première moitié si $\mathrm{XIX}^{\mathrm{e}}$ siècle et dont l'autre branche est venue s'établir en notre ville au début du XVIII ${ }^{\mathrm{e}}$ siècle ${ }^{44}$. Jean Royer, nacido aún en Sompuis en 1791 de Etienne Royer y de Marie Gourin, llegó a Langres en el primer cuarto del siglo XvIII, donde tuvo dos hijos con su esposa, Antoinette Robert, el segundo de los cuales fue Isidore Royer, de quien nacieron, a su vez, Claude-Denis y François-Marie Royer. El primogénito de este último, Nicolás Royer, fue el padre de Charles y Joseph ${ }^{45}$, los eruditos y bibliófilos que poseyeron en su biblioteca el incunable objeto de este trabajo.

Compartieron ambos hermanos el interés por el coleccionismo artístico y bibliófilo antiguo, con especial atención a la tradición local, lo que generó un verdadero museo de gran riqueza en el primer cuarto del siglo $\mathrm{xx}^{46}$, en el cual «les raretés bibliographiques, en tout cas, y occupent une place consideráble» ${ }^{47}$. Más allá de algunos manus-

${ }^{44}$ Louis Marcel, Une vieille maison bourgeoise de Langres. L'hôtel Royer: sa rue, ses anciens propriétaires, ses collections, Langres, Imprimerie Champenoise, 1920, p. 36.

${ }^{45}$ Establezco el árbol genealógico de los hermanos Royer a partir de las noticias dadas por Louis Marcel, ibid., pp. 36-38.

${ }^{46}$ L'Hôtel Royer constituía «un véritable "petit sanctuaire d'art local"», ibid., p. 47, un «musée domestique», ibid., p. 48.

${ }^{47}$ Ibid., p. 39. 
critos medievales y de otros de siglos inmediatamente posteriores ${ }^{48}$, la verdadera riqueza de la colección fueron los incunables ${ }^{49}$, entre los que se encontraban tres provenientes de la Península Ibérica: dos en latín y uno en castellano ${ }^{50}$. Dentro del interés por la producción bibliográfica que ensalzara la gloria de personajes locales anteriores a la Revolución Francesa ${ }^{51}$, destaca-como «orgueil de la collection», dice Marcel con razón- la producción del impresor Nicolas Jenson, que trabajó tres años en Maguncia bajo la supervisión de Johannes Gutenberg mismo y que en 1468 se establece como impresor en Venecia, donde murió en 1480. Los Royer lo consideraron de Langres ${ }^{52}$ y, de ahí, su interés por él. Esta colección llegó a reunir 73 ejemplares de obras impresas por Jenson ${ }^{53}$, lo que, por un lado, supone casi la mitad de su producción y, por el otro, evidencia la importancia de este fondo.

La colección de incunables no solo es muy considerable en cuanto a la cantidad de obras reunidas y a la rareza de muchos de los impresos recogidos, sino que presenta un estado de conservación excelente $^{54}$. Esto debió de ser fruto, sin duda, de su selecta procedencia, pues los ejemplares que llegaron al fondo de los Royer habían formado parte de las bibliotecas de los monarcas franceses de los siglos XVI, XVII y XVIII, así como de su entorno más cercano, hasta el punto de que el estudio de los aproximadamente 3300 ex-libris ${ }^{55}$ de esta colección

${ }^{48}$ «Les manuscrits, comme bien on pense, n’y sont ni moins nombreux ni moins précieux. On remarque parmi eux jusqu'à quatre livres d'Heures dont trois du $\mathrm{Xv}^{\mathrm{e}}$ siècle et un du XVI siècle, tous splendidement peints; un Missel du XIII ${ }^{\mathrm{e}}$ siècle; un Graduel du Xv ${ }^{\mathrm{e}} \gg$, Marcel, ibid., p. 40 .

49 «Mais voici mieux encore: voici de l'opulence. L'opulence c'est la collection des incunables», Marcel, ibid., p. 42.

${ }^{50}$ «Voici, tout à côté, les célèbres Vidas de Plutarco qui ont vu le jour à Séville, en 1471, et qui sont une véritable curiosité typographique», ibid. En Gesamtkatalog der Wiegendrucke, op. cit., se cataloga como M34497, que fecha su impresión en 1491.

${ }^{51}$ «Il faut rapprocher les ouvrages composés par des Langrois ou édités à Langres avant la Révolution. Cette partie des collections Royer est exceptionnellement riche: riche en quantité, riche aussi en qualité», Louis Marcel, Une vieille maison bourgeoise..., op. cit., p. 40.

${ }_{52}$ Aunque, en realidad y sensu stricto, no fue así: «Ce fameux perfectionneur des caractères romains auquel Langres a donné, il y a une trentaine d'années, le parrainage de l'une de ses places, n'était pas, à la vérité, originaire de Langres. Un érudit chartiste, M. Henri Stein, a prouvé, péremptoirement, il y a quelques 30 ans, qu'il était né à Sommevoire. Mais Sommevoire qui était, alors, du diocèse de Troyes, fait, aujourd'hui, partie du diocèse de Langres, en sorte qu'on peut dire que si Nicolas Jenson n'a pas été notre compatriote de son vivant, il l'est devenu après sa mort», ibid., p. 43.

${ }^{53}$ En 1920 eran aún 71, lo que indica que Royer continuó ampliando su colección de incunables hasta su muerte: «Or cet infatigable typographe est représenté dans la bibliothèque Royer par le chiffre, véritablement énorme, de soixante-et-onze ouvrages», ibid.

${ }^{54} \mathrm{Y}$, en muchos casos, con unas encuadernaciones no solo de calidad, sino procedentes de talleres de referencia, cuyo estudio podría generar importantes resultados. Para una valoración de esta colección de encuadernaciones, ibid., pp. 43-44.

55 «Il y a là des volumes aux armes d'à peu près tous les princes qui ont régné sur notre pays durant les $\mathrm{XVI}^{\mathrm{e}}$, $\mathrm{XVII}^{\mathrm{e}}$ et $\mathrm{XVIII}^{\mathrm{e}}$ siècles: Louis XII, François II, Henri III, Henri IV, Louis XIII, Louis XIV, Louis XV, Louis XVI. Les reines, naturellement, ne sont pas séparées, dans les vitrines, des princes dont elles ont partagé la souveraineté, ni les ministres des monarques 
aportaría datos y conclusiones que supondrían un importante avance para la historia del libro incunable en Francia y en Europa ${ }^{56}$.

Esta extensa colección incunable llegó junto al resto del legado de los Royer a la SHAL, sociedad de la cual habían sido miembros destacados tanto él como su hermano y con la que compartían intereses por el pasado histórico y artístico de Langres ${ }^{57}$. Esta era, de hecho, una práctica habitual entre sus miembros ${ }^{58}$, aunque la riqueza de los fondos de los Royer destacaba notablemente entre el resto de donaciones y legados, sobre todo en cuanto a la bibliofilia, sin que eso implique el demérito del resto de su colección. A pesar de que Joseph había fallecido cinco años antes, fue en 1946 cuando se produjo de facto la llegada de su legado a la Société Historique et Archéologique de Langres, un retraso motivado, sin duda, «pour éviter son pillage par l'occupant nazi», como señala Pierre Gariot; no se tuvo acceso público a sus fondos, sin embargo, hasta la reapertura de los museos de esta Sociedad en 1950, como advierte Georges Viard, el precedesor de Gariot en el cargo y hoy presidente honorífico de la institución ${ }^{59}$.

qu'ils ont servis. Catherine de Médicis voisine avec Anne d'Autriche, Marie Leckzinska avec Marie-Antionette, Richelieu avec Colbert, le président de Thou avec le chancelier Seguier. De très grandes dames, les filles de Louis XV, la marquise de Pompadour, la comtesse de Verrue on également là leurs écussons et c'est, on le comprend, une véritable joie pour les yeux et une véritable fête pour l'imagination que de regarder simplement tant de volumes à la fois si remarquablement ornés et si riches en illustres souvenirs. A ceux qu'intéresse l'étude des marques de possession du livre, la Bibliothèque Royer offre encore une autre série bien curieuse d'objets de travail, ce sont les ex-libris. Il y en a là, nous a-t-on dit, au moins trois mille trois cents qui son de toutes les époques: XVI ${ }^{\mathrm{e}}, \mathrm{XVII}^{\mathrm{e}}$ et XVIII ${ }^{\mathrm{e}}$ siècles», ibid., p. 44.

${ }^{56}$ Pues muchos de ellos acabaron, tras la Revolución Francesa, en monasterios y conventos alemanes e italianos: «Les origines anciennes des incunables sont très diverses, mais ce sont surtout les couvents et monastères allemands et italiens qui fournissent le gros de ces provenances. Les ponctions douloureuses connues en France au moment de la Révolution, n'épargnèrent pas l'Allemagne conséquences des conditions politiques et religieuses. Il n'est donc pas surprenant de rencontrer des livres échappés des monastères de Bavière, de Munich, Amberg, Bamberg, Ratisbonne, entrés dans des collections privées à la fin du XVIII ${ }^{\mathrm{e}}$ siècle. Il en est de même pour l'Italie avec les livres des couvents de Gênes, Forli et Viadana», Jean-Marie Arnoult, Catalogues régionaux..., op. cit., p. 382.

${ }^{57}$ «Dès ses origines la Société historique et archéologique de Langres s'est attachée à sauvegarder et mettre en valeur autant qu'elle le pouvait les richesses multiformes du pays lingon», J. Ch. Didier, «Langres. Société historique et archéologique», en Jean-Marie Arnoult, Catalogues régionaux des incunables des bibliothèques publiques de France, I. Bibliothèques de la Région Champagne-Ardenne, Bordeaux, Societé des Bibliophiles de Guyenne, 1979, p. 379.

58 «Ils prennent place dans la longue liste des membres de la société historique et archéologique de Langres, grands donateurs du musée, avec les Guyot de Giey, Girault de Prangey, Perron, Henry Brocard, Aubert, Colson, Forgeot et leurs noms méritent d'être rappelés», como indica el actual presidente de la SHAL, Pierre Gariot, en un documento inédito y mecanoscrito, titulado «Les frères Royer: artistes, collectionneurs émérites et donateurs du musée de Langres», que me ha facilitado Arnaud Vaillant, el director de las colecciones del Musée de Langres, lo que agradezco desde aquí.

${ }^{59}$ "Après la seconde guerre mondiale, une sérieuse cure de rajeunissement fut menée à bien dans les deux musées sous la houlette de Hubert Gillot, professeur à l'Université de Strasbourg et président de la S.H.A.L., et sa réussite saluée, lors de son inauguration, le 16 octobre 1950, par Robert Schuman, alors ministre des Affaires étrangères», George Viard, «A l'origine 
Se conserva entre la documentación de los Musées de Langres un documento manuscrito sobre este legado, sin signatura, con una introducción sobre el método de clasificación, que precede al catálogo razonado de los incunables de Jenson pertenecientes a esta colección y en la que se indica al inicio que «l'ancien conservateur du musée de Langres, Joseph Royer, a légué à ce museée plusieurs collections remarquables d'ouvres d'art, notamment 350 incunables, dont 73 imprimés à Venise par Nicolas Jenson». De esto, por un lado, se deriva que Joseph Royer, como su hermano Charles ${ }^{60}$, fueron conservadores de los museos de Langres relacionados con la SHAL y, por el otro, se nos ofrece un valioso recuento del número de incunables que llegaron en ese momento a la Sociedad, algunos de los cuales hoy ya no forman parte de ella.

Pocos meses después de que el 17 de julio de 1836 autorizara su constitución el entonces ministro del Interior, nació la Société Archéologique de Langres, impulsada por miembros como Joseph-Philibert Girault de Prangey, Jean Luquet, Théodore Pistollet de SaintFerjeux y Stanislas Migneret, y al servicio de la conservación de los bienes arqueológicos de la ciudad. Tuvo su germen, de hecho, en el censo de las antigüedades, fundamentalmente galo-romanas, encontradas en las murallas de la ciudad bajo la coordinación del fotógrafo Girault de Prangey, en colaboración con el entonces alcalde de Langres. No adquirió la denominación actual de Société Historique et Archéologique de Langres hasta 1842 y recibió el reconocimiento como institución pública en 1852, fecha de sus estatutos definitivos. Precisamente porque nacía de las actuaciones decimonónicamente arqueológicas en las murallas de la ciudad, se consideró como objetivo prioritario la creación de un museo para que conservara las antigüedades catalogadas. Es así como nació en 1841, en el ábside de la iglesia de Saint-Didier, destruida parcialmente por la Revolución Francesa, el primer Musée d'Art et Histoire de Langres, cuyo origen está absolutamente ligado, por lo tanto, al de la Sociedad propiamente dicha y al proyecto particular del arquitecto Jean Luquet.

El museo resultó insuficiente para albergar la cantidad de adquisiciones promovidas por la Sociedad durante la segunda mitad del siglo XIX y principios del Xx, lo que dio lugar a que Albert du Breuil de Saint-Germain donase el edificio que hoy ocupa la SHAL con la condición de que se utilizara para la exposición pública de los fondos arqueológicos y artísticos de que se disponía. Fue así como la Sociedad dispuso de dos museos, conocidos como el Musée Saint-Didier y el Musée Breuil, que pudieron dar acogida a nuevos materiales,

des musées de Langres: la Societé Historique et Archéologique de Langres», en Le nouveau musée de Langres, Langres, Musée de Langres, 1996, pp. 4-6, p. 5.

${ }^{60}$ «Les conservateurs, choisis parmi les membres de la Societé notamment Henry Brocard et Charles Royer, s'efforcèrent de les mettre en valeur, selon les normes muséographiques du temps», ibid. 
procedentes de compras y donaciones, entre las que se encontraba el legado de los hermanos Charles y Joseph Royer ${ }^{61}$.

Entre 1976 y 1977, la SHAL firmó un convenio con las autoridades municipales de Langres para que fuesen ellos los que se encargasen de la conservación del patrimonio y a este fin se contrató a Gérard Tisserand como primer conservador de los museos de Langres. Como fruto de este convenio nació el nuevo emplazamiento del Musée d'Art et d'Histoire de Langres, destinado a reunir los fondos de Saint-Didier y Breuil en un edificio de estilo contemporáneo, inaugurado en $1995^{62}$. Un año después, en 1996, llegan a este nuevo empl-azamiento, provenientes del Musée Breuil, los incunables de la SHAL y, entre ellos, el ejemplar único de las Orationes ad laudem purissime conceptionis virginis Marie.

\section{LA CONVOCATORIA DEL CERTAMEN: EL LIBELLUM}

Gallardo nos facilitó el íncipit, el colofón, una breve descripción física y un listado de autores de este incunable ${ }^{63}$, una información que ha servido de referente para la bibliografía posterior durante casi un siglo y medio, pero que es sesgada o errónea en algunos detalles, sobre los cuales y ante el desconocimiento del original se han generado conclusiones que deben ser revisadas, en unos casos, y matizadas o ampliadas en otros.

El íncipit transcrito por Gallardo ${ }^{64}$, en realidad, aglutina ${ }^{65}$ la invocación verbal, la rúbrica general del incunable y la del primero

\footnotetext{
${ }^{61}$ Ibid.

${ }^{62}$ Georges Viard, como presidente de la Sociedad en el momento de la inauguración del nuevo Musée de Langres, justifica que se llegara a esta cesión de fondos por motivos espaciales y financieros, que dificultaban a la Sociedad la correcta conservación de estos, aunque expresa su compromiso con las autoridades municipales para seguir nutriendo esto fondos y reconoce que, a pesar de encontrarse «libérée de la lourde charge matérielle et de l'administration des musées», la SHAL no «se désintéresse nullement de la vie de ces derniers», ibid., p. 6.

${ }^{63}$ Bartolomé José Gallardo, Ensayo de una biblioteca.., op. cit., vol. 2, pp. 797-798, n. ${ }^{\circ}$ 2047.

${ }^{64}$ Gallardo, ibid., vol. 2, p. 797, n. ${ }^{\circ} 2047$.

${ }^{65} \mathrm{La}$ aglutinación de las rúbricas se mantiene en toda la bibliografía posterior, que depende directamente de Gallardo, ibid. José Enrique Serrano y Morales, Reseña histórica..., op. cit., p. 451, cita literalmente a Bartolomé José Gallardo, Ensayo de una biblioteca..., op. cit., vol. 2, p. 797 , n. ${ }^{\circ}$ 2047, y a Konrad Haebler, Bibliografia ibérica ..., op. cit., p. 105, n. ${ }^{\circ}$ 229 , y sigue su modelo, aunque introduciendo unos puntos suspensivos tras la rúbrica del llibell, suponiendo que el texto continuaría, aunque hemos podido comprobar que no es así. Los reproduce Francisco Vindel, El arte tipográfico en España..., op. cit., p. 76, n. ${ }^{\circ}$ 26, aunque separa por primera vez en dos párrafos diferentes las rúbricas iniciales, aún aglutinadas, del colofón y esto mismo hace Antoni Ferrando Francés, Els certàmens poètics..., op. cit., p. 557, que los transcribe, por tanto, a partir de este. El Gesamtkatalog der Wiegendrucke (GW, op. cit., n. ${ }^{\circ}$ 08344) mantiene el formato de Haebler. Y, finalmente, Diego Romero Lucas, Catálogo gráfico descriptivo..., op. cit., vol. 2, p. 129, n. ${ }^{\circ} 25$, no transcribe la rúbrica inicial completa, que recorta con puntos suspensivos y, con eso, no solo la mutila, sino que suprime también la correspondiente al libellum.
} 
de sus textos, el correspondiente al libellum o llibell $^{66}$, que presenta, además, un error de omisión ${ }^{67}$ :

\title{
Yefue marie filitue. Dequentes orationes recitate fuerunt apuo inclíte fe

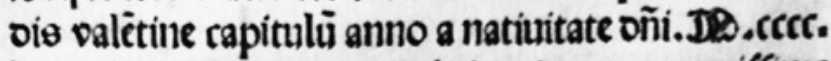 Ixxxviij. Dexto ious oecembrie. vie autem puriffime conceptionio ubi pleriqs aoerât et fenatorie et pafto/ ralis oignitatio per quoo oiligenter fuerũt juoicate. \\ Zibellum nobilis viri feroinanoi oieç peé biteri qui in lauoem puriffime matrio oñi munus obtulit.
}

\author{
(C) Collections des Musées de Langres
}

[a1r] Jesus marie filius.

Sequentes orationes recitate fuerunt apud inclite se $\mid$ dis valentine capitulum anno a natiuitate domini. M.cccc. | lxxxviij. Sexto idus decembris. die autem purissime conceptionis ubi plerique aderant et senatorie et pasto | ralis dignitatis per quos diligenter fuerunt judicate.

Libellum nobilis viri ferdinandi dieç presbiteri qui | in laudem purissime matris domini munus obtulit ${ }^{68}$.

Jesus, Marie filius es una fórmula de invocación verbal, frecuente en usos manuscritos ${ }^{69}$, frente al modelo de invocaciones simbólicas, representado por una cruz o Jhs al principio de algunos textos. Su función es delimitar el inicio de los procesos de copia, encomendando a Dios, con ello, los textos que siguen. No es tan frecuente su uso en la imprenta -aunque no desconocido- $y$, siendo este período temprano, bien podría tratarse de un rasgo del original manuscrito, que se habría mantenido en el impreso, una característica que se utiliza precediendo los textos de Ferran Dies en los otros dos incunables sobre la Inmaculada patrocinados por él, a los que me referiré después.

La rúbrica inicial, que conocíamos desde mediados del siglo XIX, ya nos informaba de que los discursos se recitaron en el Cabildo de la

${ }^{66}$ Llamado pròlech también en otros certámenes y que consiste en el texto de convocatoria del certamen, en el que, normalmente, se explicitan, además, sus reglas.

${ }^{67}$ La palabra viri en la rúbrica del libellum.

${ }^{68}$ La transcripción paleográfica de todos los textos del incunable citados en este trabajo es mía.

${ }^{69}$ Sobre todo en los copiados por notarios, por tratarse de una práctica de escritura en su documentación, al encomendarse a Jesucristo, aunque se extiende su uso. 
Catedral de Valencia, el 8 de diciembre de $1488^{70}$, como era esperable, pues así ocurrió en los dos certámenes previos ${ }^{71}$, lo que suponía una manera de honrar la festividad de la Inmaculada ${ }^{72}$, recientemente institucionalizada por Sixto IV mediante la bula papal Cum praeexcelsa, de 28 de febrero de $1476^{73}$. Nos informa, también, de que tales discursos se juzgaron diligentemente y de que se recitaron ante la mayor parte de las dignidades eclesiásticas y de los notables de la ciudad de Valencia. Poco más sabíamos, puesto que Gallardo solo nos había proporcionado la rúbrica de este libellum, mediante el cual Dies convocaba el certamen, que se limitaba a indicar que el premio era en loor de la Purísima. Es el texto en sí el que nos aporta mayor información al respecto y ahora, con la recuperación del incunable, estamos en disposición de editarlo ${ }^{74} \mathrm{y}$ conocer más datos sobre el desarrollo del certamen. Así dice el libellum:

Quemadmodum naturalis dies tripertito distinguitur in | noctem auroram et meridiem et sicut anima rationa | lis tribus est decorata potentijs scilicet intellectu memo/ / ria et voluntate ita ad instar nostri creatoris qui est vera $\mid$ trinitas omnia debent in illius immitationem

${ }^{70}$ Pues el idus de diciembre es el día 13, a lo que habría que restar seis días, según el cómputo latino. Antoni Ferrando Francés, Els certàmens poètics..., op. cit., p. 558, interpreta, sin embargo, que fue el día 9 de diciembre.

${ }^{71}$ Otra cosa es cuándo se entregaron los premios, pero la lectura siempre tuvo lugar el día de la fiesta.

${ }^{72}$ La festividad de la Inmaculada Concepción había arraigado tanto a lo largo de los tres últimos siglos, que se celebraba, incluso, aunque oficiosamente, en la mismísima Sede Apostólica de Roma. Juan de Segovia lo utilizó como argumento a favor de la Inmaculada Concepción en el Concilio de Basilea, pues era una verdad de pietate fidei: «La Iglesia no podría celebrar la Concepción si esta no hubiera sido santa en sí misma: la idea de una santificación posterior a haber contraído el pecado original estaba ya celebrada en la Natividad de la Virgen y por ello no habría tenido sentido alguno instituir una nueva fiesta distinta. Con este argumento no pretende Juan de Segovia que se trate ya de una verdad "de necessitate fidei", pero sí "de pietate fidei", es decir, no hay obligación positiva de adherir a ella, pero es ilícito negarla», Cándido Pozo Sánchez, "Culto mariano y "definición" de la Inmaculada en el Concilio de Basilea», Scripta de Maria, 3 (1980), pp. 609-631, pp. 617-618. En cualquier caso, este era, tan solo, el punto de partida, puesto que, «Una vez que se consideraba que pertenecía ya al ámbito de la piedad de la fe, sólo restaba declararla como perteneciente al ámbito de la necesidad de la fe (de necessitate fidei). Dicho con otras palabras: a nadie era ya lícito predicar o enseñar contra la doctrina inmaculista. El nuevo paso sería declarar que a esa doctrina era necesario prestar asentimiento positivo por parte de todos. Todos los católicos tendrían que aprobarla, defenderla y abrazarla», Segundo L. Pérez López, «La Inmaculada Concepción en el Concilio de Basilea y su contexto histórico», en Gozo y esperanza. Memorial Prof. Dr. Julio A. Ramos Guerreira, José Román Flecha Andrés, Miguel Anxo Pena González y Ángel Galindo García (eds.), Salamanca, Universidad de Salamanca, 2006, pp. 371-392, p. 374.

${ }^{73}$ De hecho, la bula Grave nimis, de 4 de septiembre de 1483, una nueva disposición papal de 1484, debieron ser el origen de la convocatoria del certamen inmaculista patrocinado por Ferran Dies el 1486. Mediante ambas pragmáticas, Sixto IV establece la doctrina libre sobre el misterio de la Inmaculada Concepción y prohíbe, bajo la amenaza de pena de excomunión, que puedan ser consideradas heréticas las posiciones contrarias.

${ }^{74}$ Me limitaré, en este trabajo, a la edición paleográfica, aunque estamos trabajando en la edición crítica y traducción del texto dentro del grupo y los proyectos de investigación que dirijo. 
referri. jdcirco | ego ferdinandus dieç presbiter licet indignus et in | facundus tamen concepcionis et puritatis intemeratissime | virginis dei matris deuotus volo nunc tercio in loco | tercioque stilo tantam virginis puritatem collaudare vt $\mid$ qui videlicet ritmis numerisque vulgaribus et itidem | in soluta vulgari oratione alius laudandam proposui ce/ | lebratissimam conceptionem gloriosissime semperque virgi | nis nunc quod restabat in soluta oratione latina romanaque | lingua vobis omnibus collaudandam propono exortorque sancte | deuotionis intuitu vt ad similitudinem sanctissime et | indiuidue trinitatis scilicet patris filij et spiritus sancti sic fe $\mid$ stos tres dies presentis anni ante celebratissimum eius | dem conceptionis festum in illius tanti misterij laudes $\mid[\mathrm{a} 1 \mathrm{v}]$ velitis consumere scilicet in die sabbati quo sanctus nicolaus | colend $u$ s erit atque die domenico et secunda deinde feria premium | autem dicentium vel eius qui elegantiorem ingeniosiore $m \mid$ atque eruditiore $m$ prosam et orationem suam attulerit erit $\mid$ et dabitur donum valoris et extimationis decem ducatorum | locus autem consionis ${ }^{75}$ erit in oratorio beate et gloriosissime | virginis marie alme sedis valentie. Judiciumque erit cum | et de consilio sapiencium et doctissimorum virorum tam in | sacra theologia quam in arte dicendi peritissimorum.

En su primera mitad, se desarrolla el simbolismo del número tres, lo que se fundamenta, a su vez, en tres argumentos: las tres partes del día (noche, aurora y mediodía), las tres potencias del alma (entendimiento, memoria y voluntad) y el carácter trino del Creador, a cuya semejanza Ferran Dies, como hombre devoto y tras tópicos de modestia, convoca un tercer certamen dedicado a elogiar la concepción y la pureza de la Virgen Inmaculada. Queda evidencia aquí, por lo tanto, de esta trilogía de certámenes y de las características de cada uno de ellos: el primero en ritmo y métrica vulgares, el segundo en prosa vulgar y este tercero en prosa latina ${ }^{76}$, que tuvieron lugar, tal y como nos informan sus respectivos incunables, el día de la Inmaculada de 1486, 1487 y 1488, respectivamente. En realidad, el día de esta festividad era el central de la competición y los premios se entregaban los días posteriores, incluso casi dos meses después. Este

\footnotetext{
${ }^{75}$ Contionis, 'asamblea, reunión'.

${ }^{76}$ No debía de estar establecido tal programa de certámenes inmaculistas al convocar el de 1486, como también debió de ocurrir con la ampliación de premios o joies del certamen en verso, fruto de una cierta improvisación y, de ahí, la extensión menor de algunos de ellos. Ferran Dies justifica al inicio del incunable que recoge el certamen en prosa vulgar las razones por las que lo convoca con este nuevo formato: «Per quant subjugat resta lo dir en cobles ab innumerables vicis que, per a l'art, se requir esquivar e per lo semblant, perquè en lo passat any, donant yo quatre joyes en rims, se condolien molts com en prosa plana dir no s'i podia, principalment mogut per fer més estesa la infal·lible veritat de la Puríssima Conceptió de la Mare de Déu e per condescendre a tants bons dehidors en la prosa, un robí en or engastat haurà lo mils dient, aprés de nou jorns jutjat, essent la plaça per a dir en lo insigne monestir dels frares de la Verge Maria del Carme, jorn puríssim de tan puríssima conceptió». En cuanto a este de prosa latina, se limita a decir que era «quod restabat», 'el que faltaba' de esta trilogía.
} 
de 1488, sin embargo y a diferencia del resto, comenzó antes, el 6 de diciembre, día de san Nicolás, y se desarrolló durante tres días, de nuevo aludiendo al simbolismo de la Trinidad, hasta la festividad de la Purísima, el 8 de diciembre. El libellum matiza, por tanto, la información de la rúbrica inicial en cuanto al desarrollo cronológico del certamen ${ }^{77}$, pero también lo hace respecto al espacio en que se celebró, en cualquier caso dentro de la Catedral de Valencia: no solo el Cabildo, sino también en el oratorio de la virgen María, según el momento de desarrollo del certamen.

El premio dejaba de tener un carácter simbólico o de tratarse, sensu stricto, de una joia, como el robí de los certámenes inmaculistas de 1486 y de 1487, para convertirse en diez ducados valencianos de oro, que serían «eius qui elegantiorem ingeniosiore $m \mid$ atque eruditiorem prosam et orationem suam attulerit».

Es muy interesante la declaración de intenciones de Ferran Dies en cuanto a las características del discurso ganador, pues refería, fundamentalmente, aspectos retóricos: la elegancia de la prosa latina, su ingenio y su erudición. En este último aspecto, quizás, podría estar implícita la fundamentación teológica, pero no era este el rasgo que debió de primar en la decisión última, quizás porque se presuponía en todos los participantes, que, como se especificó en el certamen de 1486, no habían de ser contrarios a las tesis inmaculistas y debían de elogiar la pureza de la concepción de María. En este mismo aspecto incidía la elección de los jueces, que no solo eran teólogos, sino también los más expertos en arte oratoria. Ante esto, no debe de sorprendernos que su ganador no fuese un teólogo, sino un reconocido autor literario de la Valencia de entonces, como veremos.

\section{EL COLOFÓN Y LA DATACIÓN DEL INCUNABLE}

Que el producto resultante de estos certámenes literarios llegase a la imprenta es, por el carácter comercial del hecho, una clara evidencia del impacto social en su contexto de producción y difusión, un contexto inmediato puesto que el primero de ellos se debió de imprimir el mismo año de la celebración del encuentro poético ${ }^{78}$, cuya convocatoria se publicó el 11 de febrero de 1474 y cuyo veredicto se leyó poco después, el 25 de marzo. Dado que los certámenes patrocinados por Dies tuvieron lugar en la festividad de la Inmaculada

${ }^{77}$ Pero también aporta datos sobre la fecha de lectura de la sentencia, que fue el 2 de febrero de 1489.

${ }^{78}$ Es lógico, por lo temprano de las fechas, que hubiese sido impreso ese mismo año, como se acepta unánimemente, ante la repercusión que tuvo el evento y el carácter circunstancial de su edición, que preveía un efecto comercial inmediato. Y esto no entra en conflicto con el asterisco de la referencia de Brian Dutton, El cancionero del siglo XV (c. 1360-1520), 7 vols., Salamanca, Universidad de Salamanca, 1990-1991, que atribuye fecha dudosa a la fuente, pues bien es cierto que no tiene colofón y la fecha no deja de ser una hipótesis, probable, posible, pero no documentada. 
Concepción, el 8 de diciembre, se llevaron a la imprenta en la primera mitad de los años siguientes, en 1487, 1488 y 1489, respectivamente, aunque de la descripción de Gallardo ${ }^{79}$ de este último incunable se deriva, como veremos, una disfunción cronológica, que afecta a su datación. Finalmente, el de san Cristóbal se celebró el 31 de agosto de 1488 y dio lugar a un incunable salido de las prensas del librero Pere Trincher el 3 de febrero de $1489^{80}$.

En la rúbrica inicial del incunable resultante del certamen en prosa latina objeto de este trabajo, se indica que los discursos se recitaron el 8 de diciembre de 1488 -«anno a natiuitate domini. M.cccc.lxxxviij. Sexto idus decembris. die autem purissime conceptionis»-, mientras que en la transcripción que hizo Gallardo del colofón se advierte que este incunable se imprimió a principios de ese mismo año, antes, por tanto, de la celebración del certamen, lo que apunta, sin duda, a que se trata de un error, pues no era la práctica habitual: «quarto kalendas marcij. anno a natiuitate domini. M.cccc.lxxxviij» ${ }^{81}$. Serrano y Morales, Haebler, Vindel y el Gesamtkatalog der Wiegendrucke ${ }^{82}$ reproducen las transcripciones de Gallardo y mantienen en la rúbrica y en el colofón el año de 1488, en números romanos; Romero Lucas ${ }^{83}$, sin embargo, introduce un nuevo error, al transcribir el colofón fechado en 1487 («M.cccc.lxxxvii»).

Las entradas bibliográficas de Copinger, Haebler y Romero Lucas $^{84}$ datan el incunable el 26 de febrero de 1488, mientras que Vindel $^{85}$ se limita a indicar el año, sin incurrir, por tanto, en el error de reconstrucción del día concreto a partir de la fórmula latina. Si diésemos por válida la fecha de 1488 , «quarto kalendas marcij» no correspondería al 26, sino al 27 de marzo, porque ese año era bisiesto, como transcriben correctamente Antoni Ferrando y el Gesamtkatalog der Wiegendrucke ${ }^{86}$. Aunque Arnoult y el ISTC aportan una doble fecha posible -el 26 de febrero de 1488 o 1489_87, con lo que abren la puerta a corregir la información de Gallardo sobre el año de

\footnotetext{
${ }^{79}$ Bartolomé José Gallardo, Ensayo de una biblioteca..., op. cit., vol. 2, p. 797, n. ${ }^{\circ} 2047$.

${ }^{80}$ Como se ha demostrado a partir del estudio de la materialidad del impreso, corrigiendo el error del colofón, que databa el incunable en 1498, Josep Lluís Martos, «Un incunable de Pere Trincher: tipografía, decoración y datación», Revista de poética medieval, 30 (2016), pp. 199-231.

${ }^{81}$ Bartolomé José Gallardo, Ensayo de una biblioteca..., op. cit., vol. 2, p. 797, n. 2047.

${ }^{82}$ José Enrique Serrano y Morales, Reseña histórica..., op. cit., p. 451; Konrad Haebler, Bibliografia ibérica..., op. cit., p. 105, n. ${ }^{\circ}$ 229; Francisco Vindel, El arte tipográfico en España..., op. cit., p. 76, n. ${ }^{\circ} 26$; Gesamtkatalog der Wiegendrucke, op. cit., n. ${ }^{\circ} 08344$.

${ }^{83}$ Diego Romero Lucas, Catálogo gráfico descriptivo..., op . cit., vol. 2, p. 129, n. ${ }^{\circ} 25$

${ }^{84}$ Walter Arthur Copinger, Supplement to Hain 's..., op. cit., p. 307, n. ${ }^{\circ}$ 1975a; Konrad Haebler, Bibliografia ibérica ..., op. cit., p. 105, n. ${ }^{\circ} 229$; Diego Romero Lucas, Catálogo gráfico descriptivo..., op. cit., vol. 2, p. 129, n. $^{\circ} 25$

${ }^{85}$ Francisco Vindel, El arte tipográfico en España..., op. cit., p. 76, n. ${ }^{\circ} 26$.

${ }^{86}$ Antoni Ferrando Francés, Els certàmens poètics..., op. cit., p. 558; Gesamtkatalog der Wiegendrucke, op. cit., n. ${ }^{\circ} 08344$.

${ }^{87}$ Jean-Marie Arnoult, Catalogues régionaux..., op. cit., p. 107, n. ${ }^{\circ} 525$ y p. 393, n. $^{\circ} 149$; Incunabula Short Title Catalogue, op. cit., n. ${ }^{\circ}$ id00192100.
} 
publicación del incunable, mantienen el error del día en la primera de las hipótesis. El Gesamtkatalog también ofrece la doble datación, pero, en este caso, con escrupuloso acierto en cuanto a la diferenciación del día concreto: «27.II.1488 oder 26.II.1489(?)» ${ }^{88}$.

En el interrogante del Gesamtkatalog está implícita la disfunción de las fechas, una duda que desarrolla el Incunabula Short Title Catalogue: «The speeches were recited on 8 Dec. 1488 but the colophon is dated $26 \mathrm{Feb} .1488$. There is therefore either a mistake in one of the dates or the book is dated in the style of the Annunciation ${ }^{89}$. El ISTC no indica, sin embargo, dónde se encontraría el origen del error, si en una mala transcripción de Gallardo, o en un error de imprenta ${ }^{90} \mathrm{y}$, en ese caso, si se localizaba en la rúbrica o en el colofón ${ }^{91}$. Antoni Ferrando sí que se plantea ambas hipótesis y considera que, sea un problema del incunable o de la transcripción de Gallardo, el error se encuentra en el colofón ${ }^{92}$.

La recuperación del incunable nos permite resolver la cuestión, pues, como ya advertía Gallardo, se conserva su colofón en la hoja c10r, también precedido de la invocación verbal Jesus marie filius, que reproduzco y edito a continuación:

${ }^{88}$ Gesamtkatalog der Wiegendrucke, op. cit., n. ${ }^{\circ} 08344$.

${ }^{89}$ Incunabula Short Title Catalogue, op. cit., n. ${ }^{\circ}$ id00192100.

${ }^{90}$ Así ocurría, de hecho, con el impreso derivado del certamen de san Cristóbal: la Obra a llaors del benaventurat lo senyor sant Christòfol, que, según la rúbrica inicial, tuvo lugar el 31 de agosto de 1488 y dio lugar a un incunable salido de las prensas del librero Pere Trincher el 3 de febrero de 1489, a pesar de que el colofón lo databa el incunable en 1498, Josep Lluís Martos, «Un incunable de Pere Trincher...», art. cit.; Josep Lluís Martos, «Un cancionero incunable valenciano: descripción bibliográfica, estructura y contextos», en La literatura medieval hispánica en la imprenta (1475-1600), María Jesús Lacarra (ed.), Valencia, Universitat de València, 2016, pp. 173-189.

${ }^{91}$ A esta confusión en la historia bibliográfica de este impreso, no solo ha contribuido su desaparición durante un siglo y medio, sino el desconocimiento que tienen y han tenido los principales repertorios internacionales del segundo incunable de esta trilogía, el correspondiente al certamen en prosa vulgar, impreso en 1488 en Valencia, también por Lambert Palmart y hoy perdido, del que Pere Bohigas extrajo microfilm en los años 60 del siglo pasado para la Biblioteca de Catalunya, que, sin embargo, según me indican en mi última consulta, han extraviado desde hace unos años.

92 «Com podem observar, o l'incunable -obra de l'impressor alemany Lamber Palmart, que desenvolupà la seua activitat a València entre el 1475 i el 1493-conté un error en la darrera datació, o Gallardo la copià malament. Atés que, com hem vist, el 9-XII-1487 es celebrà e certamen en "prosa plana", i, per tant, amb exclusió del llatí, ens inclinem a considerar que és correcta la datació de la celebració del certamen en "prosa llatina" i que l'error correspondria a la del colofó. Altrament hauríem de suposar l'existència de dos certàmens el mateix dia, un en la Seu i l'altre en el monestir dels frares de la Verge Maria del Carme, cosa possible però improbable», Antoni Ferrando Francés, Els certàmens poètics..., op. cit., pp. 557-558. 


\section{Zु efue marie filino}

\section{Zmpzeffe fuerunt pzeoicte ozationes ao laudem $\mathrm{pt}$, ruffime conceptionis virginis marie per lambertum palmart inftante nobili ac Detotiffimo viro freroinã oo oieç p̃fbite2o oigniflimo valentie quarto kalenoag marcif-anno a natiuitate Domini. $I 8^{\circ}$.cckc, Ixxxviiif.}

(C) Collections des Musées de Langres

Jmpresse fuerunt predicte orationes ad laudem pu/ | rissime conceptionis virginis marie per lambertum | palmart instante nobili ac deuotissimo viro Ferdinan | do dieç presbitero dignissimo valentie quarto kalendas $\mid$ marcij.anno a natiuitate domini. $\mathrm{M}^{\mathrm{o}}$.cccc.lxxxviiij.

Como en la rúbrica del libellum, donde Gallardo olvida la palabra viri que precede al nombre del editor o patrocinador de este impreso, aquí no se transcribe viro y, lo que es peor, se genera un error en la fecha del colofón, de 1489, que, ante su pérdida y ante la dependencia de su descripción, ha dado lugar a problemas de datación de este incunable, a pesar de que, en realidad, no los tiene.

La existencia de una doble datación, con una fecha correspondiente al certamen y otra a la impresión del incunable, es una fuente de error ante una consulta rápida del libro en los procesos de catalogación, como demuestra la historia bibliográfica del certamen poético de 1486, impreso en 1487, fechas estas que alternan en los repertorios de los siglos XVIII, XIX y Xx. Esto es, de hecho, lo que ocurrió a Arnoult, que, a pesar de tener la suerte de haber tenido en sus manos el ejemplar y de haber consultado su colofón, se limitó a transmitir la dualidad de 1488 o 1489 , muy probablemente a partir de la información de la cubierta, en la que con letra y tinta antigua se indica 1488, cuya última cifra se corrige con tinta azul contemporánea para dar lugar a 1489 .

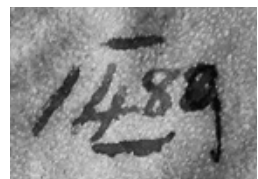

(C) Collections des Musées de Langres

Tampoco el Incunabula Short Title Catalogue solventó el error, ni sus dudas expresas, a pesar de que la British Library conserva unas microfichas de este ejemplar único del incunable, que ellos mismos 
referencian y que, sin embargo, no consultaron para su descripción ${ }^{93}$. En cualquier caso, aquí queda resuelta la cuestión cronológica, ya sin lugar a dudas, porque se documenta y se argumenta: este incunable fue impreso por Lambert Palmart en Valencia el 26 de febrero de 1489, con textos recitados entre el 6 y el 8 de diciembre de 1488 en un certamen que tuvo lugar en la Catedral valentina ${ }^{94}$, uno y otro patrocinados por el noble Ferran Dies, clérigo y devoto de la Inmaculada Concepción.

\section{LA MATERIALIDAD DE LA EDICIÓN ${ }^{95}$}

El incunable contiene 26 hojas de papel de buen gramaje, como el del impreso del certamen poético de $1487^{96}$, aunque este era casi el triple de extenso, con 72 hojas, frente a las 32 del segundo de esta trilogía, el de 1488, derivado del certamen en prosa vulgar. El uso de tinta roja para la rúbrica inicial del incunable poético es, junto a su extensión, buena prueba del mayor interés comercial que podía suponer aquel frente a los de 1488 y 1489, ambos en prosa, que son opúsculos breves ${ }^{97} \mathrm{y}$, de ahí, muy probablemente, derivan sus problemas de conservación y su desconocimiento generalizado por parte de los bibliógrafos.

Este incunable en prosa latina se estructura en tres cuadernos, sin foliación ${ }^{98}$ ni reclamos, según la colación $\mathrm{ab}^{8} \mathrm{c}^{10}$, con error de signatura en $b^{i j}$, que, en el impreso, se indica como $a^{i j}$ y que Gallardo no advertía en su descripción: $« 4^{\circ}$. -1 . g.- Hermosa impresion en

${ }^{93}$ Sobre él trabajé en la British Library yo mismo antes de mi visita a Langres de 2014, así como también visité los archivos del Gesamtkatalog der Wiegendrucke en la Staatsbibliothek zu Berlín, para buscar mayor información sobre este incunable. Agradezco a Falk Eisermann que me facilitara tanto el acceso a las fichas originales del GW, como participar en un curso de formación tipográfica previsto para las fechas de mi visita.

${ }^{94}$ Y con lectura de la sentencia el 2 de febrero de 1489, día de la Candelaria.

${ }_{95}$ Para la descripción material de ejemplar único conservado y para su posible identificación con uno o dos ejemplares de este incunable en la Biblioteca Colombina, véase Josep Lluís Martos, «Exemplar(s) d'un incunable retrobat: Orationes ad laudem Purissime Conceptionis Virginis Marie (València, Lambert Palmart, 1489)», en Miscel·lània Antoni Ferrando, Barcelona, Publicacions de l'Abadia de Montserrat, en prensa.

${ }^{96}$ Que es el único que se puede verificar, Josep Lluís Martos, «Materialitat i errors de composició d'un incunable poètic ( $\left.\mathrm{b}^{2} / 87 \mathrm{FD}\right)$ : la rendibilitat ecdòtica», Magnificat Cultura $i$ Literatura Medievals, 6 (2019). El de 1488 está perdido y solo se conserva una reproducción fotográfica.

${ }^{97}$ Esta debe de ser la razón por la que Ferrando los consideraba productos similares: «El volum que recull les composicions llatines de tots aquests poetes -curiosament molt semblant en característiques i nombre de fulles al del certamen en prosa plana de 1487-», Antoni Ferrando Francés, Els certàmens poètics..., op. cit., p. 560. Sin embargo, la recuperación del incunable de 1489 demuestra que los rasgos materiales difieren, tanto en la doble tipografía, como en la estructuración de cuadernos y, en realidad, también en la estructura de contenidos. Hay otras características formales que, frente a ello, sí que acercan ambos impresos frente al incunable poético, como el formato y la caja de escritura, a las que me referiré después.

${ }^{98}$ Impresa, pues en el ejemplar se añade a lápiz, en el margen superior derecho, solo para las 26 hojas del incunable propiamente dicho. 
buen papel, sin foliacion ni reclamos, pero con signaturas a-c (ésta de á 10 foj., las otras de á 8 foj.) ) ${ }^{99}$. Serrano y Morales ${ }^{100}$, Haebler ${ }^{101}$, Vindel $^{102}$, Ferrando Francés ${ }^{103}$, Romero Lucas ${ }^{104}$ y el Gesamtkatalog der Wiegendrucke ${ }^{105}$ reproducen estas características materiales de la edición establecidas por Gallardo, mientras que Arnoult ${ }^{106}$, que pudo ver el original, se limita a indicar que es en $4^{\circ}$, aunque, eso sí, nos aporta por primera vez un rasgo del ejemplar, como es su encuadernación en pergamino: «(Rel. parchemin)» ${ }^{107}$.

La letra es, efectivamente, gòtica, pero ni Gallardo, ni Arnoult, ni el GW, ni el ISTC concretan más. Sí que lo hace, sorprendentemente y de manera errónea, Romero Lucas: «Letra gótica de [2 tamaños]. [Tamaño grande. Gótica-4: 140-G]. Tamaño pequeño. Gótica-3: 104G. A línea tirada ${ }^{108}$. Es extraña la precisión, porque desconoce el ejemplar, del que, como advierte, no le llegó reproducción alguna, lo que es lógico, pues no se conservaba en el fondo que indicaba en su entrada catalográfica, como explico y corrijo en este trabajo. De ahí se deriva que le suponga erróneamente una doble tipografía, de dos tamaños, un rasgo del incunable en prosa vulgar de 1488 -que no cataloga y, por tanto, desconoce ${ }^{109}$, como el GW y el ISTC-, pero no de este impreso de 1489.

La medida de 20 líneas ${ }^{110}$ es de $104 \mathrm{~mm}$. En cuanto al modelo de la $M$, toda la trilogía de incunables de Lambert Palmart, patrocinada por Ferran Dies, comparten el mismo:

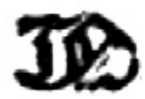

1487

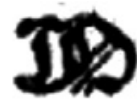

1488

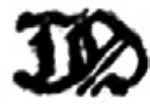

1489

${ }^{99}$ Bartolomé José Gallardo, Ensayo de una biblioteca..., op. cit., vol. 2, p. 797, n. ${ }^{\circ} 2047$.

${ }^{100}$ «En $4 .^{\circ}$ - L. g. Signats $a-c$; las dos primeras de 8 hs. y la última de $10 »$, José Enrique Serrano y Morales, Reseña histórica..., op. cit., p. 451.

${ }^{101} \ll 4^{\circ}$. - 26 hjs no fols. - sign.: $\mathrm{ab}^{8} \mathrm{c}^{10}$. — á linea tirada. - letra gótica», K. Haebler, Bibliografía ibérica..., op. cit., p. 105, n. ${ }^{\circ} 229$.

${ }^{102} « 4^{\circ} 26$ hojas sin foliar [...]. Signs. ab ${ }^{8} \mathrm{c}^{10}$. Letra gótica», Francisco Vindel, El arte tipográfico en España..., op. cit., p. 76, n. ${ }^{\circ} 26$.

${ }^{103}$ «Es tracta d'un bonic volum en quart, en bon paper, sense foliació ni reclams, de lletra gòtica i signatures $a-c$, les dues primeres de 8 fulles i la darrera de 10», Antoni Ferrando Francés, Els certàmens poètics..., op. cit., p. 557.

${ }^{104}$ «Tamaño in $4^{\circ} .26$ hojas sin foliar. Cuadernos: $\mathrm{a}^{\mathrm{a}} \mathrm{b}^{8}, \mathrm{c}^{10} »$, Diego Romero Lucas, Catálogo gráfico descriptivo..., op. cit., vol. 2, p. 129, n. ${ }^{\circ} 25$.

${ }^{105}$ «26 Bl. ab ${ }^{8} \mathrm{c}^{10}$. Typ. got.», Gesamtkatalog der Wiegendrucke, op. cit., n. ${ }^{\circ} 08344$.

${ }^{106}$ Jean-Marie Arnoult, Catalogues régionaux..., op. cit., p. 107, n. $^{\circ} 525$ y p. 393, n. $^{\circ} 149$.

${ }^{107}$ Ibid., p. 393, n. ${ }^{\circ} 149$.

${ }^{108}$ Diego Romero Lucas, Catálogo gráfico descriptivo..., op. cit., vol. 2, p. 129, n. ${ }^{\circ} 25$.

${ }^{109}$ Pues en caso contrario, lo habría catalogado. Podemos pensar que extrapola la tipografía 3:104G del primer incunable de la trilogía, el de 1487, pero ¿de dónde determina su hipotética doble tipografía, distinguiendo sus tamaños e, incluso, precisando los tipos?

${ }^{110}$ Tomada a partir de las páginas a3r-v, porque son las primeras que no presentan líneas en blanco en la caja de escritura. En cualquier caso, compruebo esta medida en hojas posteriores y se confirma, lo que también indica la calidad de conservación del papel, que no se ha contraído por humedad. 
Este diseño no coincide con ninguno de los ofrecidos por Haebler, aunque el más parecido es M51, de rasgos puntiagudos frente a un mayor redondeamiento del modelo de estos impresos de Palmart. El Typenrepertorium der Wiegendrucke cataloga este modelo como M16B, correspondiente a la tipografía que identifica como ma12185 111 :

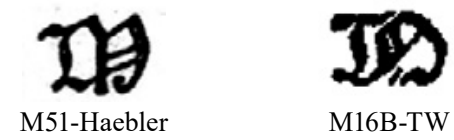

El Gesamtkatalog der Wiegendrucke no atribuye una tipografía gótica concreta a este incunable de $1489^{112}$, pero sí que lo hace al primero de esta trilogía, el de $1487^{113}$, que identifica como el tipo 3:104/105G de Lambert Palmart ${ }^{114}$, documentado por este catálogo en nueve incunables salidos de su taller, en un arco temporal que va desde 1482 hasta $1492^{115}$. A estos nueve habría que añadir, por tanto, otros dos: los incunables de 1488 y 1489, pues la trilogía inmaculista se imprime con esta tipografía (3: 104G), si bien el de 1488 alterna un tipo de mayor tamaño en los íncipits de las hs. 1v-2r.

No disponíamos de datos sobre la caja de escritura, que es a línea tirada $^{116}$, compuesta de 28 líneas $^{117}$ y de 146 x $91 \mathrm{~mm}$. El tamaño del papel de esta edición era, al menos, de 215 x $152 \mathrm{~mm}$, que son las medidas de este ejemplar. Gallardo nos indicaba que era «buen papel $\rangle^{118}$, pero no si contaba con filigranas, como, de hecho, ocurre: las podemos encontrar en el cosido central de las hs. a2, a3, a6, a7,

${ }^{111}$ TW-Typenrepertorium der Wiegendrucke, en línea: <https://tw.staatsbibliothek-berlin. de/> [consulta: 24/06/2019]. Comparto con el TW la identificación de esta M con el modelo M51 de Haebler.

${ }^{112}$ Gesamtkatalog der Wiegendrucke, op. cit., n. ${ }^{\circ} 08344$.

${ }^{113} \mathrm{Ibid} ., \mathrm{n}^{\circ} 08343$.

${ }^{114}$ La define Salvà como «letra gótica mui clara, por ser poco angulosa y bastante gruesa», Pedro Salvá y Mallén, Catálogo de la biblioteca de Salvà, 2 vols., Valencia, Imprenta de Ferrer de Orga, 1872, vol. 1, p. 141, n. ${ }^{\circ}$ 301. Por esta definición, duda Konrad Haebler, Bibliografía ibérica..., op. cit., p. 105, n. $^{\circ} 228$, en un principio, de que el modelo tipográfico de esta letra sea el habitual de Palmart, aunque cambia de opinión tras localizar y estudiar Ernst el incunable de 1487 conservado en la Biblioteca Universitària de Barcelona, de cuyos datos concluye Haebler que «es la letra común de texto, que Palmart empleó para todos sus libros en gótico», Konrad Haebler, Bibliografia ibérica del siglo XV. Segunda parte, Leipzig-La Haya, Karl W. Hiersemann-Martinus Nijhoff, 1917, p. 63, n. ${ }^{\circ} 228$.

${ }^{115}$ En total, serían los impresos que el Gesamtkatalog der Wiegendrucke, op.cit., cataloga como GW 00057, 0005710N, 00060, 00061, 0125950N, 08343, 10428, 10430 y M10417.

${ }^{116}$ Como imaginó Konrad Haebler, Bibliografia ibérica.., op. cit., p. 105, n. ${ }^{\circ} 229$, al tratarse de textos en prosa, pues no conocía el ejemplar.

${ }^{117}$ Comprobadas en las hh. a3r-a6v, que no presentan líneas en blanco. La signatura de cuaderno no computa en ningún caso en el número de líneas.

${ }^{118}$ Bartolomé José Gallardo, Ensayo de una biblioteca..., op. cit., vol. 2, p. 797, n. 2047. 
b2, b4, b5, b7, c1, c2, c3, c4, c7, c8, c9 y c10, además de la guardas iniciales, que son de papel de época ${ }^{119}$.

Los cuadernos $a$ y $b$, formados por dos pliegos conjugados y con solaridad entre los bifolios a2-a7, a3-a6, b2-b7 y b4-b5, a la luz de las filigranas, presentan una estructura regular y previsible. No queda tan claro, sin embargo, el modelo de composición del cuaderno $c$, que no parece responder al esquema de dos pliegos conjugados y medio pliego central, sino a alguna solución más compleja. Como confirma la continuidad de la filigrana, las hojas c4-c7 presentan solidaridad y el hecho de que el bifolio c5-c6 sea el único de este cuaderno que no tiene marca de agua parece apuntar a que ambos pertenecen a un mismo pliego. Este estaría en la posición interna del cuaderno y lo enmarcarían tres medios pliegos exteriores (c1-c10, c2-c9 y c3-c8), todos ellos con filigrana, lo que no permite otro esquema: una estructura de cuaderno, por tanto, muy interesante por infrecuente.

Todas las filigranas responden al modelo de la mano, pero con diseños diferentes, aun siendo todas manos enguantadas (a2 y c10): con estrella de 5 puntas (c4) o manos de cuatro dedos juntos y pulgar con diferentes grados de inclinación en la separación de los dedos (cfr. a7 frente a c1, c8 y c9), con base del pulgar más (b7a, c2 y c3) o menos abombada (a3, b5 y c7), con elipse redondeada (a7, b7, c2 y c3) o más puntiaguda (a3 y c7) en la unión del pulgar y el dedo índice, que, a su vez y por ello, tiene más inclinación en unos casos que en otros. La identificación de estas filigranas con los modelos de Briquet $^{120}$ es una tarea bastante compleja, por ser todos de un mismo modelo (la mano) y por encontrarse aquí en el cosido, pero sí que podemos identificar, al menos, cuatro filigranas diferentes: la de las guardas anteriores, con iniciales, e, indudablemente, la del bifolio a2-a7, la del bifolio a3-a6 y la del bifolio b2-b7, aunque es muy probable que haya algún otro diseño ligeramente diferente entre la variedad del cuaderno $c$.

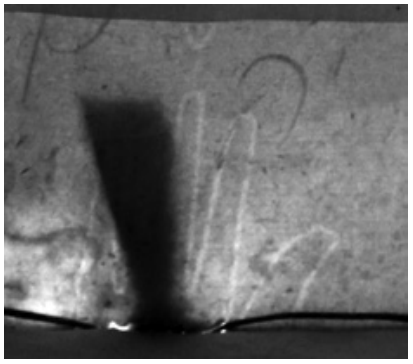

guarda anterior 1

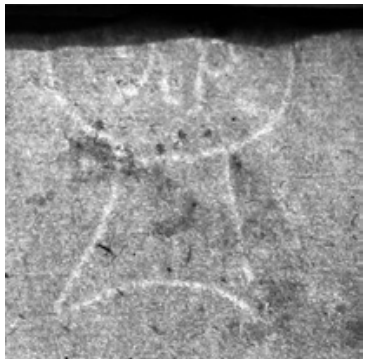

guarda anterior 2

${ }^{119}$ Agradezco a Anne-Guylaine Foret que me haya confirmado algunas medidas del incunable y que me haya proporcionado las fotografías de todos los folios al trasluz en la zona de filigranas, que no tomé en mi visita de 2014.

${ }^{120}$ Jacques M. Briquet, Les filigranes. Dictionnaire historique des marques du papier dès leur apparition vers 1282 jusqu'en 1600 [1907], 4 vols., Karl W. Hiersemann, Leipzig, 1923. 


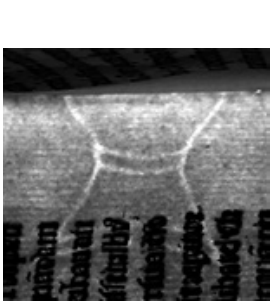

a2

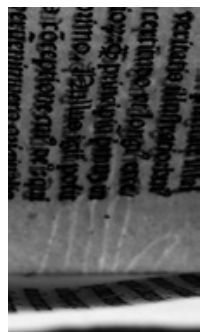

b2

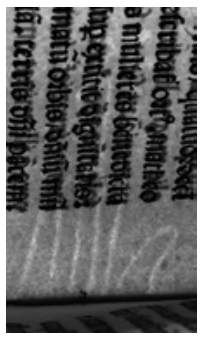

c1

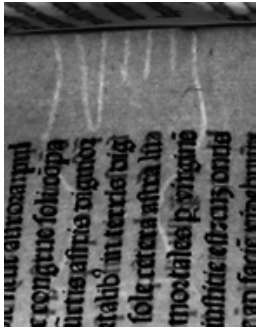

c7

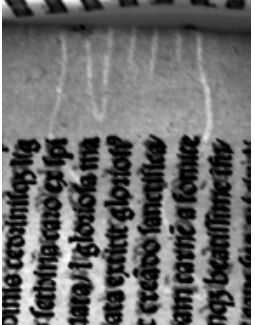

a3

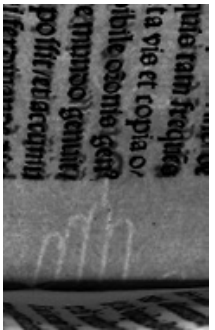

b4

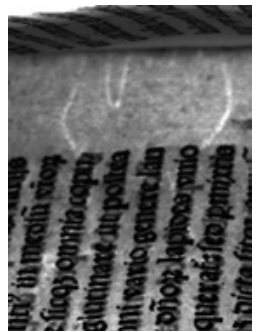

c2

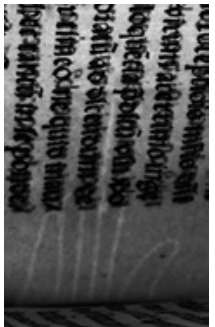

$\mathrm{c} 8$

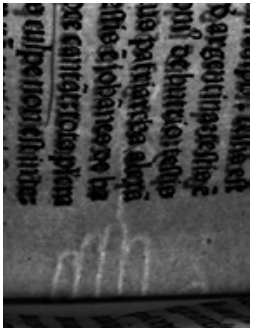

a6

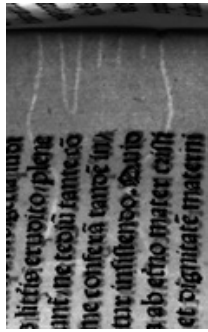

b5

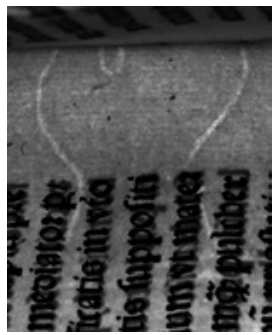

c3

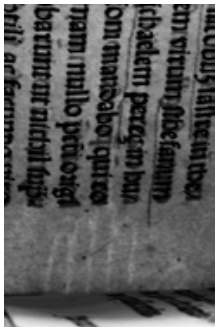

c9

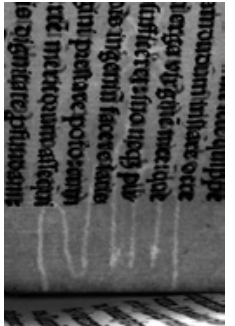

a7

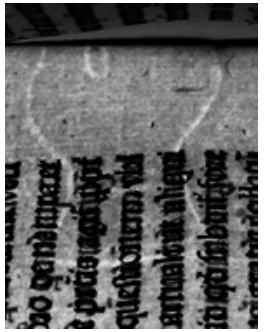

b7

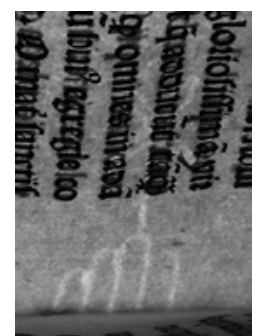

c4

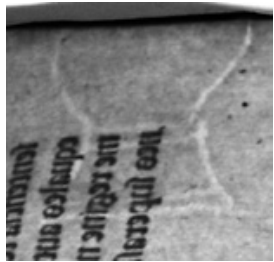

$\mathrm{c} 10$

(C) Collections des Musées de Langres Fotografías: Anne-Guylaine Foret

Los corondeles del papel son horizontales, con mucha distancia entre ellos, y los puntizones verticales ${ }^{121}$, lo que, junto a la localización de la filigrana, nos confirma que, efectivamente, se trata de un

${ }^{121}$ Anne-Guylaine Foret me facilita una fotografía al trasluz de la h. a1 y me confirma la distancia entre cada uno de los corondeles, tomada desde el margen superior al inferior: 37 , $38,40,39,41$ y $20 \mathrm{~mm}$, respectivamente; los puntizones están muy juntos, con una distancia de menos de $1 \mathrm{~mm}$. 
impreso plegado in $4^{\circ}$, tal y como había descrito Gallardo y como se ha reproducido hasta la actualidad. La confirmación, necesaria en cualquier caso, cobra mayor sentido porque, del primer incunable de la trilogía, también se afirmó mayoritariamente que era in $4^{\circ}$, mientras que, en realidad, es un volumen in $8^{\text {ol22 }}$, un rasgo material que contrasta entre ambos impresos. Las diferencias en el plegado generan, especialmente en este caso, un menor tamaño del incunable poético de 1487, cuyo papel debió de tener un mínimo de 166 x 118 $\mathrm{mm}^{123}$, frente a los 215 x $152 \mathrm{~mm}$ de este impreso de 1489. Debió de ser, sin duda, su contenido lo que determinó su formato, no solo por la mayor manejabilidad de un impreso poético, sino por el aprovechamiento del papel, dado que el verso reducía la caja de escritura notablemente. De hecho, contrastan las medidas de esta en ambos impresos, de 130 × $76 \mathrm{~mm}^{124}$ y de 25 líneas ${ }^{125}$ en el de 1487, más limitada que los 146 x $91 \mathrm{~mm}$ y las 28 líneas ${ }^{126}$ del incunable de 1489 , objeto de este trabajo. Aunque del segundo impreso de la trilogía, el de 1488 , solo se conserva reproducción fotográfica y, por ello, no podemos comprobar físicamente sus medidas y formato, sí que hay un rasgo material que conocemos y que resulta determinante, sobre todo a la luz del contraste de datos entre los otros dos incunables: las 28 líneas de la caja de escritura, que justificarían un formato similar al del impreso latino de 1489 , en cuanto al plegado in $4^{\circ} \mathrm{y}$ a las dimensiones de la caja de escritura. Esto apuntaría, de nuevo, al verso como la principal razón para el diferente formato y tamaño del primer incunable de la trilogía frente a los dos siguientes, ambos en prosa.

Entre las características materiales de esta trilogía de incunables, destaca la diferente praxis en cuanto a su inicio: el impreso de 1487 debía de tener una hoja completa de portada, probablemente en blanco (a1) -perdida en los dos ejemplares conservados-, porque el texto y la rúbrica inicial en tinta roja comienza en la hoja a2r; el texto del impreso de 1488 empieza en a1v, por lo que es muy probable que a1r estuviese en blanco; y, finalmente, este impreso de 1489 no presenta ningún formato de portada y su texto comienza directamente en la hoja a1r, con una rúbrica inicial con idéntica tipografía a la del libellum, razón por la cual, a pesar de estar separadas ambas por una línea en blanco, Gallardo debió de aglutinarlas en su descripción ${ }^{127}$.

\footnotetext{
122 Josep Lluís Martos, «Materialitat i errors...», art. cit.

${ }^{123}$ Como se concluye a partir de las medidas máximas de los dos ejemplares conservados: Barcelona, CRAI-Fons de reserva-Universitat de Barcelona, 166 x 113 mm; Nueva York, Hispanic Society of America, 165 x $118 \mathrm{~mm}$.

${ }^{124}$ Extraída de i7v, i8r e i8v, que contienen textos en prosa y, por tanto, con medidas estables de la caja, frente a los folios con verso, que son la mayoría.

${ }^{125}$ Muy excepcionalmente 26 líneas, cuando hay problemas de impaginación, para lo que remito a Josep Lluís Martos, «Materialitat i errors...», art. cit.

${ }^{126}$ Comprobadas en las hh. a3r-a6v, que no presentan líneas en blanco. La signatura de cuaderno no computa en ningún caso en el número de líneas.

${ }^{127}$ Bartolomé José Gallardo, Ensayo de una biblioteca.., op. cit., vol. 2, p. 797, n. ${ }^{\circ} 2047$.
} 


\section{LA ESTRUCTURA INTERNA DEL INCUNABLE}

A diferencia del incunable poético de 1487, cuya compleja estructura interna reproduce Gallardo ${ }^{128}$, con referencia a rúbricas, íncipits, hojas en que se copian e, incluso, cierta información métrica de los textos, de este impreso en prosa latina no presenta el esquema de contenidos concretos ${ }^{129}$. Tampoco lo hacen Arnoult, el GW ni el ISTC $^{130}$, aunque aquí se debe a las características intrínsecas de estos catálogos. No teníamos constancia hasta hoy, por tanto, de las obras que contiene este incunable, para cuya estructura interna transcribo la rúbrica inicial y el colofón, así como la rúbrica, el íncipit, el éxplicit y las hojas que ocupa cada uno de sus textos:

Jesus marie filius. | Sequentes orationes recitate fuerunt apud inclite se | dis valentine capitulum anno a natiuitate domini. M.cccc. | lxxxviij. Sexto idus decembris. die autem purissime $\mid$ conceptionis ubi plerique aderant et senatorie et pasto/ | ralis dignitatis per quos diligenter fuerunt judicate. (a1r).

Libellum nobilis viri ferdinandi dieç presbiteri qui | in laudem purissime matris domini munus obtulit. Inc.: Quemadmodum naturalis dies tripertito... Expl.: ...sacra theologia quam in arte dicendi peritissimorum. (a1r-v).

Oratio per nobilem ac purissime matris domini concepcionis deuotissimum auctoritate judicis fungentem in principijs | orationum habita his diebus quibus cetere recitate fuerunt. | Jntroitus judicis. Inc.: Cum mecum ipse reuerendi... Expl.: ...et in fut/ | turo perpetuam felicitatem dabit. (a1v-a2r).

Oracio eloquentissima in laudem purissime matris domini | conceptionis habita per magnificum virum michae/ | lem pereç que merito omnes superasse meruit. Inc.: Explicaturus ego quid de celeberrime virginis... Expl.: ad regna me $\mid$ reantur peruenire celestia// Amen. (a2v-a7r).

Oratio suptilissima in laudem purissime matris do $\mid$ mini conceptionis habita per doctissimum et suptilis | simum virum iohannem lopiç in theologia studentem $\mid$ que in aliquo vocabulo fuit emendata. Inc.: Fulgentissimum de ineffabili virginis puritate.... Expl.: ...Exul | temus:et letemur in ea. (a7v-b4r).

\footnotetext{
${ }^{128}$ Ibid., vol. 2, pp. 793-797, n. ${ }^{\circ} 2046$.

${ }^{129} \mathrm{Ibid}$., vol. 2, p. 797, n. ${ }^{\circ} 2047$.

${ }^{130}$ Jean-Marie Arnoult, Catalogues régionaux..., op. cit., p. 107, n. ${ }^{\circ} 525$ y p. 393, n. ${ }^{\circ} 149$; Gesamtkatalog der Wiegendrucke, op. cit., n. ${ }^{\circ}$ 08344; Incunabula Short Title Catalogue, op. cit., n. ${ }^{\circ}$ id00192100.
} 
Trihunphus in laudem purissime conceptionis matris | domini per reuerendu $m$ nostrum matheum pereç in theologia $\mid$ professore $m$ sacri ordinis purissime virginis marie de gratia ${ }^{131}$. Inc.: De tam magnis grauibus que rebus... Expl.: ...omnes videbimus lumen hic per gratiam / et in | futuro per gloriam // Amen. (b4r-c2r).

Oratio habita ab eloquentissimo viro hieronimo bel | luga vtriusque iuris doctore in laude $m$ purissime con $\mid$ ceptionis matris domini. Inc.: Nouissime post multos alios viros sciencia... Expl.: ...submitto me sancti | matri ecclesie / doctoribus prelatisque eiudem. (c2r-c5r).

Oracio habita ${ }^{132}$ in laudem purissime concepcionis matris | domini habita per eloquentissimum oratorem dominum stefanum | costa presbiterum dignissimum ${ }^{133}$. Inc.: Et si consultius mihi fore certo scio... Expl.: ....nomenque tuum laudesque manebunt. (c5v-c8r).

Jesus marie filius. | Oratio per nobilem ac deuotum virum ferdinandum dieç | presbiterum dignissimum et in hac purissime matris nostre | conceptionis materia ${ }^{134} \ldots$ Inc.: Maximum et amplissimum mun $u$ s et humeris meis... Expl.: ...glorie participes faciet absque fine. amen. (c8r-v).

Jesus marie filius. | Sentencia qua visum est per huius vrbis famosissimos | theologos orationem/ primam michaelis pereç omnes | sequentes superasse. Inc.: Si quis vestrum est viri doctissimi qui forte admiretur... Expl.: ...nostre laudibus michaelem pereç hos om/ | nes superasse censeo. (c9r-c10r).

Jesus marie filius | Jmpresse fuerunt predicte orationes ad laudem pu/ | rissime conceptionis virginis marie per lambertum | palmart instante nobili ac deuotissimo viro Ferdinan $\mid$ do dieç presbitero dignissimo valentie quarto kalendas $\mid$ marcij.anno a natiuitate domini. $\mathrm{M}^{\mathrm{o}}$.cccc. lxxxviiij. (c10r).

[en blanco] (c10v).

El único dato de que disponíamos en cuanto a los contenidos de este impreso era la nómina de oradores o participantes que nos había

\footnotetext{
${ }^{131}$ Esta rúbrica no presenta línea de separación respecto del final del texto anterior.

${ }^{132}$ La repetición de habita se debe a la influencia de la rúbrica anterior, de Jeroni Belluga, con estructura sintáctica diferente a las que preceden a los textos de Miquel Peres y Joan Llopis. En el caso de Belluga, el participio se encuentra en la primera parte de la rúbrica y rige la preposición $a b$, mientras que en las rúbricas de Peres y Llopis está en la segunda parte, cuyo régimen es la preposición per, como en esta de Esteve Costa, razón por la cual habría que eliminar este primer participio.

${ }^{133}$ Esta rúbrica no presenta línea de separación respecto del texto que encabeza.

${ }^{134}$ Se trata de una amplia rúbrica descriptiva, de extensión similar a la del texto que precede, cuya transcripción completa y análisis forma parte de otro trabajo.
} 
proporcionado Gallardo hace un siglo y medio. Sin embargo, con la recuperación del incunable y con la delimitación de su estructura interna, tenemos constancia, por primera vez, de los textos que, fehacientemente, Ferran Dies decidió incorporar a él, con lo que ello implica, pues la selección se limitó tan solo a cinco orationes, lo que contrasta con los ocho oradores y el juez recogidos por Gallardo:

GALLARDO $^{135}$

Autores DE ORATIONES EN EL INCUNABLE

«Los oradores fueron:

Pedro Adriá.

Miguel Perez.

michaelem pereç

Juan Lopiz.

Mateo Perez.

iohannem lopiç in theologia studentem matheum pereç in theologia professorem

Dr. Jerónimo Belluga, in utroque. hieronimo belluga vtriusque iuris doctore

Estéban Costa, presbítero. stefanu $m$ costa, presbiterum

Fernando Perez, juez.

Pedro Gozalbo.

Juan Lonch».

Aquí queda esta discrepancia ${ }^{136} \mathrm{y}$, junto a ella, la evidencia de los textos recuperados, encabezados por la oratio ganadora, la de Miquel Peres, siguiendo la práctica común en estos impresos ${ }^{137}$. Tras la suya, se incorpora la oratio de un estudiante en teología, Joan Llopis, por cuya rúbrica sabemos «que in aliquo vocabulo fuit emendata»; y, después, la del bien conocido teólogo Mateu Peres, de una extensión similar a las dos anteriores. No es así, sin embargo, en el caso de las orationes de Jeroni Belluga, «vtriusque iuris doctore», y del presbítero Esteve Costa, de tan solo tres hojas cada una.

\section{EN DEFINITIVA, LITERATURA RECUPERADA}

La incorporación de la obra de un estudiante en teología en una posición tan privilegiada como la segunda, que en el resto de certámenes valencianos del Xv tuvo siempre una razón de ser, avala la calidad del texto, más desde la perspectiva retórica que teológica, pues su interés también radica en el hecho de que se haya revisado para ser impresa, una revisión que, sin duda, debió de ser teológica. Esta circunstancia y que, precisamente, ganase el certamen Miquel Peres, quien «in hu/ | manitatibus disertissimum obliuioni mandabo

${ }^{135}$ Bartolomé José Gallardo, Ensayo de una biblioteca..., op. cit., vol. 2, p. 798, n. 2047.

${ }^{136}$ Que estudiaré en otro trabajo, pues los objetivos de este se limitaban a la localización y recuperación del incunable, a la reconstrucción de su historia bibliográfica hasta su llegada al fondo actual, a su estudio material y a la constatación de su estructura interna.

${ }^{137}$ Así se indica en la rúbrica: «habita per magnificum virum michae/ | lem pereç que merito omnes superasse meruit». Es una información, de hecho, reincidente en el incunable, desde el cuerpo de los textos, a la rúbrica de la sentencia. 
qui eo $\mid$ dem modo uirginem gloriosissimam nullo peccati origi | nalis fornite fuisse deturpatam probarunt» $(\mathrm{c} 9 \mathrm{v})$, deja entrever que este fue un certamen literario y no solo teológico. Ambos aspectos son los que lo definen desde el libellum, pues Ferran Dies lo concluye -y no olvidemos que es la convocatoria del certamen- advirtiendo que los jueces serán especialistas tanto en teología, como en artes dicenci: «Judiciumque erit cum $\mid$ et de consilio sapiencium et doctissimorum uirorum tam in $\mid$ sacra theologia quam in arte dicendi peritissimorum» (a1v).

Este impreso, por tanto y en definitiva, debe estudiarse y contextualizarse en el marco de otros certámenes literarios valencianos del siglo Xv, en general, y en el de esta trilogía de encuentros e incunables patrocinados por Ferran Dies en loor de la Inmaculada Concepción, en particular.. Las obras que contiene, a su vez, deben ayudar a completar la visión que teníamos de autores literarios de la Valencia de entonces y deben interpretarse a la luz del resto de su producción literaria. Y es que, en definitiva, esta es la razón de ser del estudio de la literatura perdida; más aun debe serlo cuando, como en este caso, lo que se ofrece a la crítica especializada y a la cultura de un pueblo es la recuperación de su patrimonio literario.

Recibido 24/07/2019

Aceptado: 1/10/2019 
(2)

\title{
ORATIONES AD LAUDEM PURISSIME CONCEPTIONIS VIRGINIS MARIE: RECUPERACIÓN DE UN INCUNABLE / LITERATURA RECUPERADA
}

\begin{abstract}
RESUMEN: El estudio de la literatura perdida no solo amplía el catálogo de obras conocidas de un autor, de un género o de una tradición, para reconstruir, así, la producción literaria, sino que permite abordar algo aún más importante: la recuperación, total o parcial, de los textos. Aquí radica la importancia de este trabajo, que recupera y estudia un incunable perdido desde el siglo XIX, cuyas obras eran hasta hoy desconocidas textualmente: Orationes ad laudem Purissime Conceptionis Virgini Marie (Valencia, Palmart, 1489).
\end{abstract}

PAlabras ClaVe: Literatura perdida, incunable, Lambert Palmart, bibliografía material, Inmaculada Concepción, Langres.

\section{ORATIONES AD LAUDEM PURISSIME CONCEPTIONIS VIRGINI MARIE: THE RECOVERY OF AN INCUNABULUM / RECOVERED LITERATURE}

\begin{abstract}
Studying lost literature allows us both to expand the catalogue of known works of a given author, a genre, or a tradition, thus rebuilding the literary production, and to address something still more important: the total or partial recovery of texts. This is where the relevance of this essay lies which recovers and studies an incunable lost since the nineteenth century, whose works were unknown until this moment: Orationes ad laudem Purissime Conceptionis Virgini Marie (Valentia, Palmart, 1489).
\end{abstract}

KeYwords: Lost literature, incunabulum, Lambert Palmart, material bibliography, Immaculate Conception, Langres. 